\title{
PRINCIPLES OF CLIMATE RISK MANAGEMENT FOR CLIMATE PROOFING PROJECTS
}

Paul Watkiss, Robert Wilby, and Charles Andrew Rodgers

NO. 69

July 2020

\section{ADB SUSTAINABLE DEVELOPMENT WORKING PAPER SERIES}




\section{ADB Sustainable Development Working Paper Series}

\section{Principles of Climate Risk Management for Climate Proofing Projects}

Paul Watkiss, Robert Wilby, and Charles Andrew Rodgers

No. 69 | July 2020
Paul Watkiss is the director of Paul Watkiss Associates, and works as a senior adaptation consultant for the Asian Development Bank (ADB).

Robert Wilby is a professor of hydroclimatic modelling at the School of Social Sciences and Humanities, Loughborough University, United Kingdom.

Charles Andrew Rodgers is a senior climate change risk management and adaptation consultant at ADB. 
(C) 2020 Asian Development Bank 6 ADB Avenue, Mandaluyong City, 1550 Metro Manila, Philippines

Tel +632 8632 4444; Fax +63286362444

www.adb.org

Some rights reserved. Published in 2020.

Publication Stock No. WPS200203-2

DOI: http://dx.doi.org/10.22617/WPS200203-2

The views expressed in this publication are those of the authors and do not necessarily reflect the views and policies of the Asian Development Bank (ADB) or its Board of Governors or the governments they represent.

ADB does not guarantee the accuracy of the data included in this publication and accepts no responsibility for any consequence of their use. The mention of specific companies or products of manufacturers does not imply that they are endorsed or recommended by ADB in preference to others of a similar nature that are not mentioned.

By making any designation of or reference to a particular territory or geographic area, or by using the term "country" in this document, $A D B$ does not intend to make any judgments as to the legal or other status of any territory or area.

This work is available under the Creative Commons Attribution 3.0 IGO license (CC BY 3.0 IGO)

https://creativecommons.org/licenses/by/3.0/igo/. By using the content of this publication, you agree to be bound by the terms of this license. For attribution, translations, adaptations, and permissions, please read the provisions and terms of use at https://www.adb.org/terms-use\#openaccess.

This CC license does not apply to non-ADB copyright materials in this publication. If the material is attributed to another source, contact the copyright owner or publisher of that source for permission to reproduce it. ADB cannot be held liable for any claims that arise as a result of your use of the material.

Please contact pubsmarketing@adb.org if you have questions or comments with respect to content, or if you wish to obtainc copyright permission for your intended use that does not fall within these terms, or for permission to use the ADB logo.

The ADB Sustainable Development Working Paper Series presents data, information, and/or findings from ongoing research and studies to encourage exchange of ideas and elicit comment and feedback about development issues in Asia and the Pacific. Since papers in this series are intended for quick and easy dissemination, the content may or may not be fully edited and may later be modified for final publication.

Corrigenda to ADB publications may be found at http://www.adb.org/publications/corrigenda.

Note:

In this publication, "\$" refers to United States dollars. 


\section{CONTENTS}

TABLES, FIGURES, AND BOXES vi

ABSTRACT vii

ACKNOWLEDGMENTS viii

ABBREVIATIONS $\quad$ ix

EXECUTIVE SUMMARY $\quad$ xi

$\begin{array}{lll}\text { I. INTRODUCTION } & 1\end{array}$

II. MOVING THE PROCESS UPSTREAM-THE STRATEGIC LEVEL 4

III. PROJECT CONCEPT PHASE

$\begin{array}{ll}\text { IV. PROJECT PREPARATION PHASE } & 10\end{array}$

A. Climate Proofing (Type 1) Projects Suitable for Light-Touch 11 Climate Risk and Adaptation Assessment

B. Climate Proofing (Type 1) Projects Requiring In-Depth 23 Climate Risk and Adaptation Assessment

C. Adaptation (Type 2) Projects 25

V. STRENGTHENING DOWNSTREAM-THE IMPLEMENTATION LEVEL 26

$\begin{array}{lr}\text { VI. CONCLUSION } & 27\end{array}$

$\begin{array}{ll}\text { GLOSSARY } & 30\end{array}$

$\begin{array}{ll}\text { REFERENCES } & 32\end{array}$ 


\section{TABLES, FIGURES, AND BOXES}

\section{TABLES}

1 Examples of Project Suitability Assessment for In-Depth vs. Light-Touch

Climate Risk and Adaptation Assessment

2 Economic Categories for Climate Change Risk Assessment 13

3 Adaptation Type, Timing and Economic Rationale 19

\section{FIGURES}

A Proposed Guiding Principles of Climate Risk Management xi for Climate Proofing Projects

1 Climate Risk Management Framework 1

2 The Climate Risk and Adaptation Assessment Process 6 and the Project Concept Phase

3 The Climate Risk and Adaptation Assessment Process 10 and the Preparation Phase

4 The Climate Risk and Adaptation Assessment Process 26 and the Implementation Phase

5 Principles for Updating ADB's Climate Risk Management and Climate Risk 28 and Adaptation Assessmen for Climate Proofing (Type 1) Projects

\section{BOXES}

1 Review of ADB's Climate Risk Management Process 2

2 Climate Risk and Adaptation Assessment Pilot Studies 10

3 Light-Touch Case Studies and Rapid Risk Assessment 14

4 Economic Analysis of Climate Proofing Investment Projects 18

5 Light-Touch Climate Risk and Adaptation Assessment Case Studies 21

6 Policy and Regulatory Interventions 22

$7 \quad$ Case Studies on In-Depth Climate Proofing Projects 24 


\begin{abstract}
This working paper identifies opportunities to update the Asian Development Bank (ADB) climate risk management (CRM) process and climate risk and adaptation assessments (CRAs). The intent is to streamline the CRM framework with a fit-for-purpose approach, and to improve the quality and consistency of CRAs. To this end, a set of guiding principles aligned with the three main phases of the ADB project cycle-conceptualization, preparation, and implementation-is presented here. The principles highlight the value of a more strategic method for upstream activities, as well as the benefits of a differentiated approach, in view of the varying CRA needs of projects. Specific principles are proposed for improving the main CRA steps, with a focus on project understanding and decision-led risk assessment, and on the prioritization of adaptation options. Finally, the paper emphasizes the need to strengthen downstream activities, to ensure that good practice flows into implementation. The paper provides useful lessons and insights into climate risk management for ADB and its developing member countries, as well as information relevant to climate risk assessments of investments.
\end{abstract}




\section{ACKNOWLEDGMENTS}

This working paper was prepared by the Climate Change and Disaster Risk Management Division, Sustainable Development and Climate Change Department (SDCC), of the Asian Development Bank (ADB). It draws on comments and input from sector and thematic group participants at the ADB staff training workshop on climate risk and adaptation assessments, held in Manila on 22-23 November 2018.

Arghya Sinha Roy, senior climate change specialist (climate change adaptation), SDCC, led the development of the paper, building on activities begun by Xianfu Lu, former senior climate change specialist (climate change adaptation), SDCC. ADB consultants Paul Watkiss, Robert Wilby, and Charles Andrew Rodgers developed the paper. Sugar Gonzales, climate change officer (climate change adaptation), SDCC, provided invaluable overall coordination support in its finalization.

The paper benefited significantly from discussions with and input received from Noelle O'Brien, principal climate change specialist, Pacific Department (PARD); Nathan Rive, senior climate change specialist, Central and West Asia Department; and PARD consultants Dennis Fenton and Jeffrey Bowyer. 


\section{ABBREVIATIONS}

$\begin{array}{ll}\text { ADB } & \text { Asian Development Bank } \\ \text { COBP } & \text { country operations business plan } \\ \text { CPS } & \text { country partnership strategy } \\ \text { CRA } & \text { climate risk and adaptation assessment } \\ \text { CRM } & \text { climate risk management } \\ \text { DMC } & \text { developing member country } \\ \text { DMUU } & \text { decision making under uncertainty } \\ \text { EIRR } & \text { economic internal rate of return } \\ \text { IPCC } & \text { Intergovernmental Panel on Climate Change } \\ \text { MDB } & \text { multilateral development bank } \\ \text { PAM } & \text { project administration manual } \\ \text { TRTA } & \text { transaction technical assistance }\end{array}$




\section{EXECUTIVE SUMMARY}

The Asian Development Bank (ADB) has been implementing a climate risk management (CRM) approach since 2014. This is a mandatory part of project development. Climate risk screening is applied to all ADB investments, with a more detailed Climate Risk and Adaptation assessment (CRA) undertaken for projects that are assessed to be at medium or high risk. ADB has commissioned a number of reviews of the CRM process and of recent CRAs. These have identified opportunities for improving internal CRM procedures and for enhancing the quality of project CRAs. ADB has also highlighted climate resilience as an operational priority in its Strategy 2030 and announced a cumulative climate financing commitment of $\$ 80$ billion between 2019 and 2030. This will expand climate investment opportunities, but will also require strengthening of operational processes and project-level guidance. Against this background, this working paper provides guiding principles for applying the CRM processes.

This document presents a new set of guiding principles for CRM and CRAs for climate proofing projects in ADB. It focuses on climate risks to development projects, rather than on targeted climate adaptation projects. The aim is to help to improve the overall CRM framework with a fit-for-purpose approach, and to improve the quality and consistency of CRAs. The initial principles were formulated in 2018, then discussed and amended during a workshop in November 2018. These were road-tested and revised using two ADB project CRAs undertaken in early 2019. The principles are presented below, sequenced in line with the $A D B$ project cycle and the CRM framework. While these principles are primarily intended at ADB CRM, they also provide useful lessons and insights into climate risk management for ADB's developing member countries (DMCs).

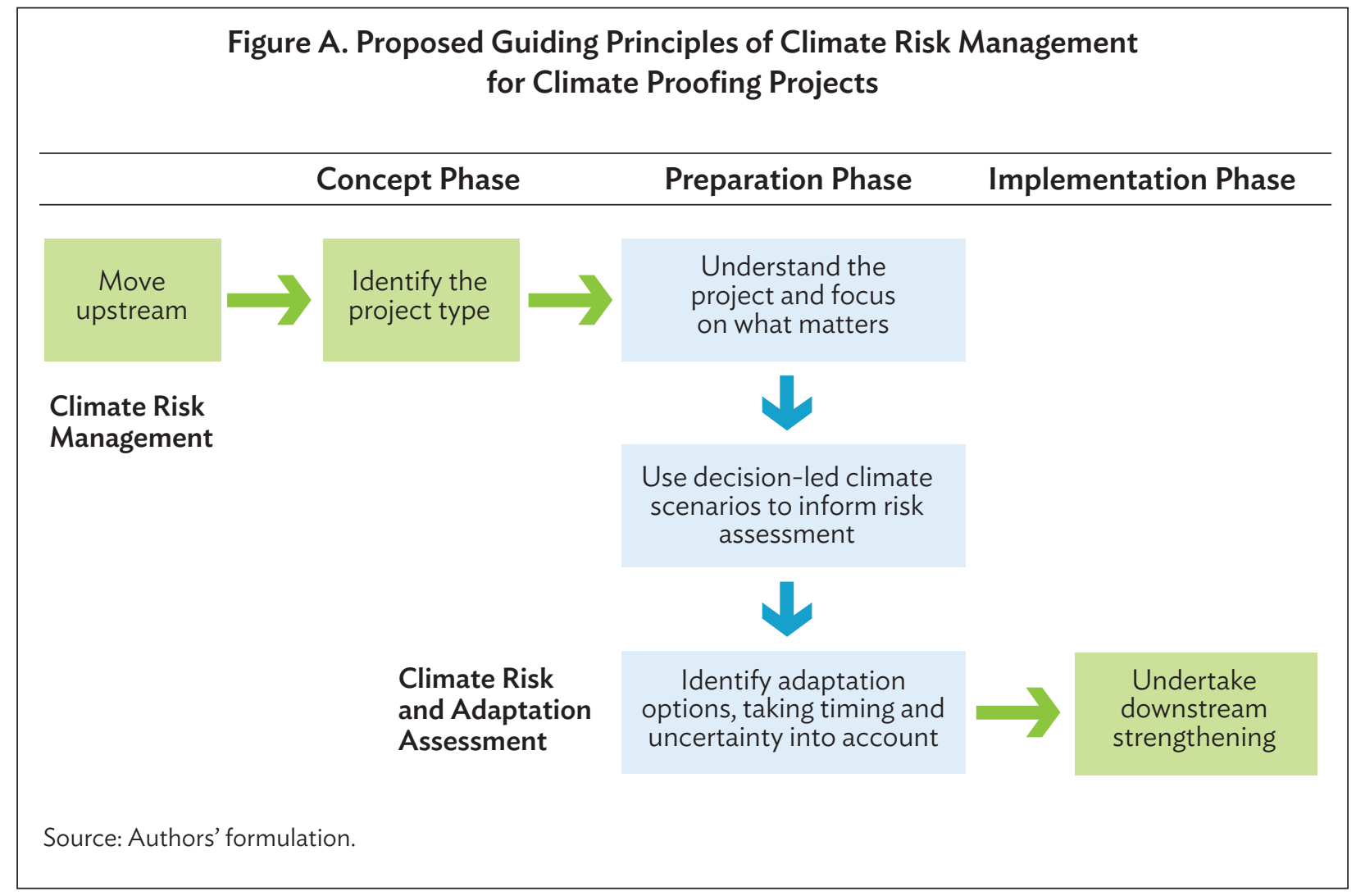




\section{STRATEGIC LEVEL}

There is generally a limited scope to redesign or alter a project significantly to increase climate resilience once the concept phase is complete. Therefore, a key priority is to move CRM procedures upstream to enable the strategic analysis of climate risks and climate programming for country engagement, thematic operational planning, and sector assesment.

Principle 1: The CRM process should begin upstream, including in the country partnership strategy, to identify climate change risks for regions, sectors, and communities. This informs and supports the development of a pipeline of adaptation projects and climate proofing activities.

\section{CONCEPT PHASE}

In the first main phase of the project cycle, ADB has applied a broadly consistent approach to most projects for CRM and CRAs. However, ADB invests in various types of climate projects, which require different levels of analysis and resources. The review found that the existing CRA technical guidance is resource- and time-intensive to implement for projects, and that a lighter touch approach would be welcome. This led to the second principle.

Principle 2: The type of climate proofing project-and suitability for light-touch assessmentshould be identified early on in the concept phase to ensure that the time and resources required for fit-for-purpose CRA are secured. The lifetime, degree of lock-in, level of precaution needed, and project size should be considered.

Based on the review and workshop findings, the recommended project differentiation is between:

- Type 1 projects, which are focused on climate proofing of proposed development investments, i.e., where adaptation is a secondary objective, such as enhancing resilience in a planned road project. These projects can either be

- suitable for light-touch climate risk assessment; or

- warrant a more in-depth CRA analysis because climate risks and opportunities are highly material to the project.

- Type 2 projects, which are focused on climate adaptation, i.e., where addressing climate risks is the primary objective (e.g. coastal protection to manage rising sea levels).

Implementing this project differentiation would require some updates to the CRM process, and the climate risk screening approach, as well as a differentiated approach for CRAs. To help differentiate Type 1 projects during the early concept risk screening, an initial checklist has been developed using five criteria: (i) level of climate finance, (ii) lifetime, (iii) risk of lock-in, (iv) level of precaution warranted, and (v) potential economic impact. 


\section{PREPARATION PHASE}

This next step in the project cycle involves CRA for medium- or high-risk projects. The relevant principles are set out below, according to project type.

Climate proofing (Type 1) projects requiring only a light-touch CRA. The review of existing CRAs revealed that many studies begin with a detailed assessment of future climate change. This makes the CRA very science-led and focused on the long term. A recommendation is made to focus on understanding how current climate risks, as well as future climate change, could affect the project. It is also important to identify priority risks for the project, including key indicators, and to identify adaptation objectives at an early stage.

Principle 3: The CRA should begin by focusing on what matters: understanding key climate risks that can affect the project objectives and outcomes. Climate projections come later.

The CRA process then moves on to the risk assessment phase. The review of existing CRAs and workshop feedback highlighted that many CRAs report general climate change information with low relevance to project performance or outcomes. Therefore, more targeted climate information should be sourced, focusing on key risk metrics using light-touch assessment and sensitivity testing, rather than detailed modeling. This leads to the next principle.

Principle 4: The project risk management context should determine the selection and use of climate information, i.e., this should be "decision-led".

This can be achieved with sensitivity tests or simple rules-of-thumb to understand the scale of risk involved. This is the point when climate information can be considered, and ADB has produced a compendium of information sources to support climate risk assessments and management (issued in 2018) to help with this step. It is also important to consider how climate risk could affect the economic performance of the project.

The next step in the process is the adaptation assessment. The adaptation objective should be revisited and specified at the start. The subsequent task is identifying all adaptation options. Existing CRAs focused heavily on engineering or structural (technical) options. A recommendation is to ensure wider consideration of nontechnical and alternative options. It is also recognized that adaptation assessment for long-lived infrastructure is challenging-due to uncertainty-and because of economic analysis and reduction in future adaptation benefits (in present value terms, when compared with up-front costs). The ADB report on the economics of climate proofing recognizes these issues and offers suggestions for addressing them through detailed economic analysis. However, ADB teams have found it difficult to implement the required level of detail. There is therefore a need for light-touch approaches to adaptation assessment. Promising adaptation options for projects should be identified, the type and timing of adaptation matched to the nature of the risks, and no- and low-regret adaptation options prioritized.

Principle 5: Early adaptation options should be identified, given the timing and the degree of uncertainty.

Climate proofing (Type 1) projects requiring in-depth CRA. Principles 3-5 are also relevant to more detailed climate proofing projects, i.e., where climate risks and opportunities are highly material to the project. There are, however, some minor differences. 
Principle 3 is recommended for in-depth CRAs where it is even more important to start by understanding the project, assessing how climate risks could affect project objectives and outcomes, and defining the adaptation objectives early on. The focus on using decision-led climate information (Principle 4) is highly relevant as well, though this needs to be applied in the context of detailed climate risk analysis rather than light-touch analysis. For in-depth CRA, it will be necessary to undertake a detailed modeling of climate risks, focusing on key indicators and working closely in collaboration with the transaction technical assistance (TRTA) team. Principle 5 is also applicable for detailed climate proofing projects. The general approach of identifying early promising options, and taking account of uncertainty, still applies. However, when major design changes are involved, a greater focus is needed on adaptive management and decision-making under uncertainty.

It would be useful to identify and map which projects in the ADB portfolio are likely to require in-depth CRA. This could be used to develop more detailed CRA technical guidance for common project types, noting that this could be taken forward through sector or project specific guidance. This move is in line with recent initiatives among the multilateral development banks to develop targeted guidance, such as the Hydropower Sector Climate Resilience Guide (2019) prepared by International Hydropower Association.

\section{IMPLEMENTATION PHASE}

It was highlighted in the workshop that the CRM and CRA guidance requires further strengthening in the implementation phase. This applies to all projects, but there are additional challenges for flexible and iterative programming due to long-term implementation and governance arrangements. There are also opportunities to enhance the monitoring and evaluation framework and to incorporate more learning strategies in CRM.

Principle 6: CRM activities should encompass downstream implementation, including activities to enable more flexible and iterative adaptation, and to enhance mechanisms for monitoring, evaluation and learning.

Targeted adaptation (Type 2) projects. While the focus of this working paper is on climate proofing (Type 1) projects, the exercise has also generated some insights for adaptation (Type 2) projects. The most important insight is that for adaptation projects, Principle 1 (moving upstream) is even more pertinent to ensure that a strategic consideration of climate risks leads to a pipeline of adaptation investment projects. Type 2 projects should ideally emerge from a country, sector, or region-wide assessment of climate risks. Therefore, the climate risk assessment may be applied to the region, sector, or community itself, distinct from the project. Once projects are developed, climate change risks should form the basis for the concept note problem tree, and the core outputs, outcomes, and key indicators should be related to adaptation. A key recommendation is to further develop upstream activities, as well as the CRM framework and guidance, to enhance Type 2 project development and analysis.

\section{CONCLUSION AND NEXT STEPS}

Taken together, these guiding principles form the basis for updating ADB's CRM process and CRAs for climate proofing projects. They provide a foundation for developing strategic as well as project-level guidance, and for enhancing the frameworks and processes-ready for the scaling-up of climate finance 
associated with Strategy 2030. A number of next steps are highlighted to build on these principles and take forward the update of the CRM and CRAs. These are as follows:

- Rolling out the new principles, including providing training within ADB and its DMCs;

- Developing upstream CRM activities, targeting the entry points of the country partnership strategy, country operations business plan, sector operational plans and pre-concept phase, and establishing good practice examples of strategic analysis;

- Introducing a differentiated decision tree in the CRM system for climate proofing (Type 1) projects, reflecting both light-touch and in-depth CRAs. It would also be useful to undertake an initial appraisal of the likely categorization of common projects in the ADB portfolio between these two CRA types.

- Compiling a set of good practice examples and knowledge products for light-touch Type 1 CRAs, and developing CRA guidance and supporting material, including rapid assessment guidance (aligned with sector strategies);

- Developing detailed CRA guidance for in-depth climate proofing (Type 1) projects, with focused support for major project investment types, and creating draft terms of reference that integrate these activities into the main TRTA analysis, with supporting good practice studies.

- Enhancing the economic and financial analysis of climate risks and adaptation using the same principles outlined above. This should include differentiated approaches for light-touch and in-depth CRAs, and would benefit from economic case studies. It should also include materials to support the economic analysis of light-touch projects (e.g., benchmarking costs, look-up tables, good practice case studies).

- Undertaking further work to overcome the barriers to downstream adaptation implementation, and developing good practice examples for ADB.

- Developing a more structured process for learning within the CRM framework.

Finally, it is recommended that a similar exercise be undertaken for adaptation (Type 2) projects, including a set of principles, from the strategic level through the project cycle. 



\section{INTRODUCTION}

1. The Asian Development Bank (ADB) has been implementing a climate risk management (CRM) framework (Figure 1) since 2014 (ADB 2014c). Application of the CRM framework is mandatory in all $A D B$ investments and runs from the early concept phase of a project through project implementation. The early steps include a preliminary climate risk screening using a checklist, followed by detailed screening at the concept phase. For projects identified as being at medium or high climate risk, a more in-depth assessment-a climate risk and adaptation assessment (CRA), formerly called as climate risk and vulnerability assessment (CRVA) -is undertaken during the project preparation phase. The CRA includes a technical and economic appraisal of adaptation options for the project design. The CRM framework also encompasses a monitoring and reporting component, as the project moves into implementation.

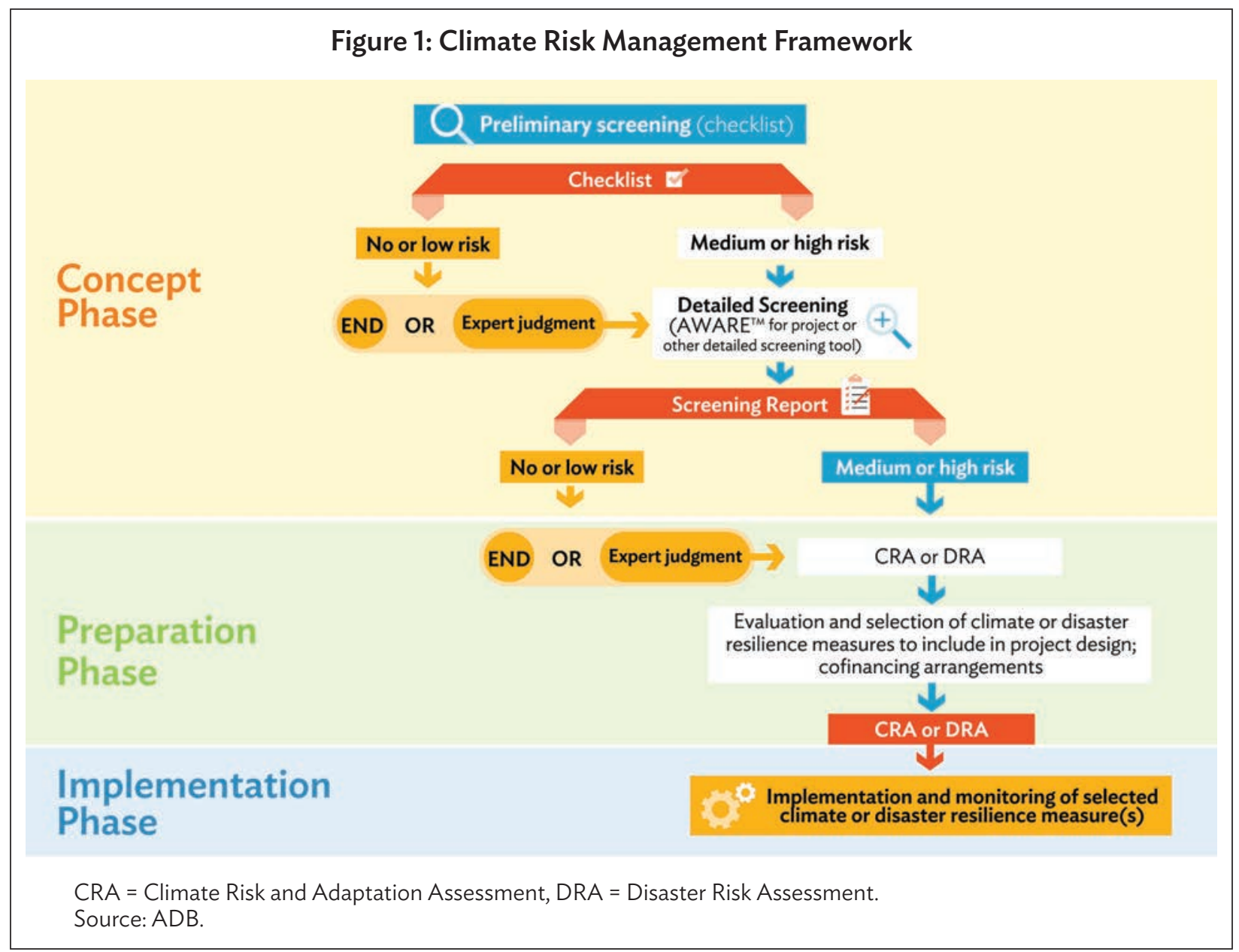

2. In 2017, ADB evaluated the CRM framework and the associated process, by commissioning reviews of existing CRAs, to identify opportunities to improve internal procedures and to strengthen the overall quality of project level climate risk management (Box 1).

3. $\mathrm{ADB}$ also increased its commitment to climate financing, as part of its new Strategy 2030 (ADB 2018c). This aims to achieve a prosperous, inclusive, resilient, and sustainable Asia and Pacific. Tackling climate change, building climate and disaster resilience, and enhancing environmental sustainability is one of the seven operational priorities of Strategy 2030. To deliver this, ADB will scale up climate investment support. As stated in the Strategy: 
ADB will ensure that $75 \%$ of the number of its committed operations (on a 3-year rolling average, including sovereign and non-sovereign operations) will be supporting climate change mitigation and adaptation by 2030 . To ensure this, climate finance from ADB's own resources will reach $\$ 80$ billion cumulatively from 2019 to 2030 .

Meeting the climate targets of Strategy 2030 will require expanding the investment opportunities for climate programming, while implementing more stringent accountability and transparency standards. It will also necessitate the strengthening of operational frameworks, processes, and strategic as well as project-level guidance.

\section{Box 1: Review of ADB's Climate Risk Management Process}

In 2017, the climate risk management (CRM) process and technical guidance on climate risk management and climate-resilient investment of the Asian Development Bank (ADB) was reviewed. This investigated practical application of the CRM framework with a detailed review of a sample of Climate Risk and Adaptation Assessments (CRAs). ${ }^{a}$ This review made a number of recommendations, including the following:

- integrate CRM considerations earlier in the project cycle, in the country partnership strategy and the country operations business plan, to ensure climate-resilience opportunities are identified before the project design is fixed;

- strengthen aspects of the current CRM guidance, especially for uncertainty analysis and the identification of adaptation options, as well as on the use and sourcing of climate change information; and

- improve the analysis of the costs and benefits of adaptation to support the programming of adaptation, as well as adaptation finance tracking.

The review also recommended a series of next steps as follows:

- create an annotated list of ADB-accredited climate risk information sources;

- compile a compendium of climate risk management options that are relevant to ADB's regional and sectoral investment priorities;

- develop terms of reference (for consultants) to set out the expected elements of CRAs; and

- Investigate further the economic analysis of adaptation options (and, in the long-term, produce worked examples).

Some of these recommendations have already been implemented. For instance, a compendium of climate risk information sources for climate risk assessments has been produced (ADB 2018b). A scoping review of the economics of adaptation in ADB has also been completed (Watkiss 2018), which led to a series of recommendations for economic analysis in climate risk and adaptation assessments.

Note: ${ }^{2}$ In earlier guidance material, these were referred to as climate risk and vulnerability assessments (CRVAs). Sources: Wilby, Robert L. 2017. Strengthening ADB Business Processes: Project Level Guidance and Operational Frameworks for Climate-Resilient Investments. Report submitted to the Asian Development Bank. Manila; author's formulation. 
4. Against this background, ADB is updating its existing CRM processes and technical guidance, including the CRA guidance, through an iterative consultation process. This has reflected on past experience, as well as future needs, with ADB project teams. Possible updates to existing CRA approaches have been piloted, i.e., these have been "road-tested" to find out what works, before updated guidance is produced. The aim of these updates is to enhance pragmatic CRM methods that are fit-for-purpose, and to help improve the quality and consistency of CRAs.

5. This paper is targeted at ADB project officers and captures the overall review process and proposes a new set of guiding principles for the ADB CRM framework and, in particular, for CRAs. It centers on ADB's main focus to date, which is on the climate proofing of proposed investments, i.e., where adaptation is a secondary objective (Type 1 projects). A preliminary set of principles were formulated in late 2018. The principles were then presented, discussed and amended during the ADB Staff Training Workshop on Climate Risk and Adaptation Assessments held in Manila on 2223 November 2018. 'Suggestions and inputs from participants were extremely beneficial in enhancing the initial principles, and providing case study material on good practice. Following the workshop, the principles were updated, and then "road-tested" in two ADB project CRAs, undertaken in early 2019. The resulting lessons were used to refine the principles, as well as to provide case study material for subsequent technical guidance updates. The resulting principles aligned with the main steps in the ADB project cycle and the CRM framework (Figure 1), are set out in following sections.

6. The review process also included discussions of targeted adaptation projects, i.e., where adaptation is the principal objective rather than climate proofing (Type 2 projects). Many of the principles presented here have high relevance for these projects as well. This paper includes a short discussion of these, but a key recommendation is the need for a more detailed look at the strategic approach for these projects, including the CRM. This is particularly important given the likely scale-up of such investments in the region.

7. This paper likewise calls attention to the strong links between CRA and disaster risk assessment (DRA). ADB has produced technical guidance on DRA during project preparation (ADB 2017a), to provide a basis for integrating disaster risk considerations into the design and implementation of individual projects. Data sources for DRA analysis and information about disaster risk reduction interventions are part of the guidance. The updated CRM should therefore also seek to cross-reference and align with ADB's DRA guidance.

8. While much of this paper-and the principles-are specific to ADB and the CRM process, it also provides useful lessons about climate risk management in the Asia and Pacific region for developing member countries (DMCs), as well as insights for the wider community of practice on climate risk management and climate risk assessment of investments.

\footnotetext{
As part of the activities to review ADB's project climate risk management processes and practices, a training session was organized on 22-23 November 2018 held in Manila to brief operations teams on the exsting CRM and proposed principles. The two-day session was structured around a series of five modules. The principles set out in this working paper were used to build a revised CRM training course, which was piloted at the Annual Training on Climate Risk Management, held in Manila on 12-14 November 2019.
} 


\section{MOVING THE PROCESS UPSTREAM-THE STRATEGIC LEVEL}

9. The current ADB CRM framework is focused at the project level and aligned with the existing ADB project cycle. However, as highlighted by the climate review (Box 1), as well as the experience of CRA practitioners, there is generally limited scope to significantly change a project design, once it has moved beyond the concept paper stage. This means that it is difficult to make major changes to the location or the type of outputs to be financed. Hence, the focus tends to be on minimizing climate risks for the project outputs during the project preparation phase.

10. A key priority, therefore, is to move the CRM procedures "upstream" to create opportunities for integrating CRM before the project cycle. This includes greater consideration of climate change at the strategic and country level, as well as in project pipeline development. The country partnership strategy (CPS) and country operations business plans (COBPs) ${ }^{2}$ are the important entry points for climate-resilient investment at the strategic level, and are the key steps for ADB's involvement in financing investments. Understanding of climate risk at a strategic, sector, or geographic area can help in the identification and prioritization of climate-resilient investments and raise awareness of key risks. The early stage of ADB project development also includes pre-feasibility work. There is also an opportunity to consider climate risks and opportunities between the development of the project pipeline (project identification) and the early stages of concept development for individual projects.

11. It is important to note that for both strategic and pre-concept considerations, there are two types of adaptation-related projects. These are:

- Climate proofing of projects. This refers to undertaking climate risk screening and assessment for projects that are in the current ADB portfolio, i.e., with standard development objectives (e.g., a road project), with the aim of improving the climate resilience of such projects. ADB often refers to these as Type 1 projects (ADB 2016b). Climate proofing focuses on the adaptation responseand the marginal costs and benefits of adaptation-to address potential climate risks or take advantage of opportunities. This increases the climate resilience of investments (also known as "adaptation in projects"). These are the main focus of this paper.

- Climate adaptation projects. This focuses on investments where adaptation is the primary objective (or one of the primary objectives). These projects will also have high climate adaptation finance tracking allocations, e.g., $40 \%$ to $100 \%$ of the total project investment. ${ }^{3}$ ADB often refers to these as Type 2 projects. These involve targeted adaptation projects (e.g., a new coastal defence project to address rising sea level), rather than climate proofing of existing projects as above. ${ }^{4}$ These are likely to become a larger part of the ADB investment portfolio in the future. Targeted adaptation projects may also leverage international climate finance (for example, with the Green Climate Fund). This type of project involves building climate resilience through investment (also sometimes called "adaptation through projects"). This paper also considers these projects briefly, but recommends further work is needed to develop ADB's approach to these projects, recognizing these may warrant a different approach.

2 The CPS is ADB's primary platform for designing operations to deliver development outcomes at the country level. ADB works with each DMC to map out a medium-term development strategy and a three-year COBP for implementing it.

3 This also relates to the Rio markers of the Organization for Economic Co-operation and Development (OECD) Development Assistance Committee (OECD 2016).

4 Noting that there will be differences in the initial climate risk screening, i.e., a Type 2 project may itself not be particularly vulnerable to climate risks, as the target is resilience rather than climate proofing. 
12. For both project types, there is a need for earlier strategic analysis of climate change. This places greater emphasis on consultations among ADB resident mission staff, sector specialists, and with governments, during the strategic steps and before the project concept is fixed. An earlier strategic focus on climate risks will help identify adaptation (Type 2) projects. An example is ADB's NDC Advance facility, an ongoing initiative that provides support for "first-mile" project development to bridge the gap between general adaptation priorities and actual, bankable project concepts. The earlier consideration of climate risks will also provide earlier climate risk context for climate proofing (Type 1) projects, helping to avoid major issues and highlighting key climate concerns. A key priority is to move CRM procedures upstream to enable a more strategic analysis of climate risks and identification of adaptation opportunities as part of country programming. This leads to the first proposed principle for the CRM process update.

Principle 1: The CRM process should begin upstream, including in the country partnership strategy, to identify climate change risks for regions, sectors, and communities. This informs and supports the development of a pipeline of adaptation projects and climate proofing activities.

13. For strategic programming, this will necessitate greater integration (mainstreaming) of climate change considerations into country and sector strategy development and plans, notably within the CPS and COBPs. Two aspects are highlighted:

- First, there is a need to include climate risk information in these plans. There are early examples of positive steps towards this at the national level with the new ADB-World Bank country climate profiles (ADB and World Bank Group, forthcoming). There are also good examples at the sub-national level, with the work being undertaken by the Urban Climate Change Resilience Trust Fund (UCCRTF), which has undertaken regional and city resilience assessments for selected cities and introduced the concept of a resilience academy which brings together relevant city level stakeholders to identify priorities for strengthening resilience. ${ }^{5}$ These can help in identifying climate resilient investment priorities, though there is a need to translate these into investment pipelines and incorporate them in results frameworks. There may also be opportunities to embed more adaptive management thinking at the upstream stage. It is highlighted that ADB's Strategy 2030, and the associated goals for climate finance, will help incentivize these changes, including the potential for more Type 2 projects.

- Second, it is important to consider the economic rationale for climate programming in country level analysis, in line with ADB economic guidance (ADB 2017a). This includes the economic importance of climate change-something that $A D B$ previously advanced through a series of studies on the regional economics of climate change, covering East Asia (ADB 2013a), Pacific (ADB 2013b), South Asia (ADB 2014a), Southeast Asia (ADB 2015a), and the Central and West Asia (ADB 2016a). However, the evidence now suggests that the economic impacts of climate change could occur much earlier, and be much larger, than indicated in these earlier studies, especially in Asia and the Pacific (OECD 2015). There is thus a greater need to consider these risks in core development planning. To advance this, there is a need for a greater consideration of the climate risks in the CPS, along with an analysis of the justification for ADB to intervene. This will necessitate an examination of barriers (e.g., market or policy failures) that prevent countries and sectors from adapting, and ways in which ADB can address these impediments.

$5 \quad$ Regional and city urban resilience assessments funded by the UCCRTF. 
14. These upstream and strategic level considerations should cascade down to project identification and early concept development (and the concept paper). However, there are also opportunities to further enhance climate considerations at the pre-concept and early concept development stages, including in the eligibility and prioritization criteria. This is also the stage at which conversations with DMC counterparties can include discussions about the costs of achieving climate resilience, and options for financing, including potential co-financing from climate funds such as the Green Climate Fund (GCF).

\section{PROJECT CONCEPT PHASE}

15. As per existing practice, a preliminary climate risk screening is undertaken during the concept phase as part of the CRM process. For projects where the climate change risk is identified as medium or high, a CRA is subsequently undertaken during the project preparation phase (next section). The current steps are shown in Figure 2.

16. To date, ADB has applied a broadly consistent approach to CRM and CRAs for all projects at the concept stage, and throughout the subsequent CRA process. However, the review work and workshop participants identified that even within Type 1 projects, there are various types, which have different needs, require different levels of resources and analysis, and could require potentially different team structures when undertaking the CRA. This highlights the need for a more differentiated approach.

\section{Figure 2: The Climate Risk and Adaptation Assessment Process and the Project Concept Phase}
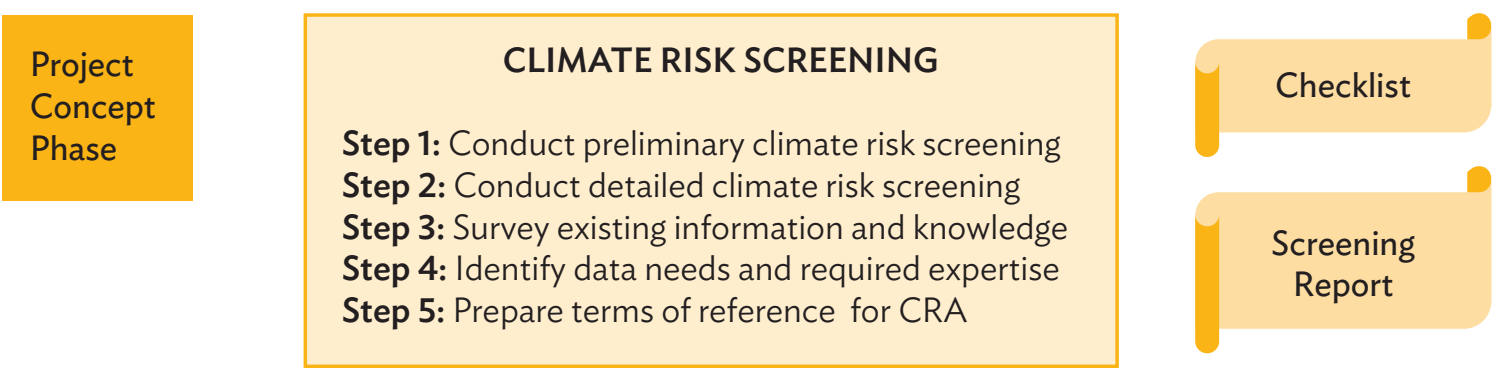

CRA = climate risk and adaptation assessment.

Source: Asian Development Bank (ADB). 2015a. Economic Analysis of Climate-Proofing Investment Projects. Manila.

17. As explained earlier, Type 1 and Type 2 projects have different objectives and are aligned to different climate finance allocations. The latter is set out by the Rio Markers for Climate of the Organization for Economic Co-operation and Development (OECD) Development Assistance Committee (DAC) (OECD 2016). ${ }^{6}$ ADB and other multilateral development banks (MDBs) apply the joint MDB methodology for tracking adaptation finance (AfDB et al. 2019).

18. For climate proofing (Type 1) projects, the review and workshop feedback revealed the highly resource- and time-intensive nature of the current CRA guidance. Project teams often request a lighter-touch CRA analysis, as resources for many CRAs are limited. However, further analysis and discussion highlighted several important differences in the portfolio of existing climate proofing projects.

\footnotetext{
6 These distinguish between expenditures that pursue climate adaptation goals as a primary objective (leading to 100\% climate finance allocation), compared to projects where climate adaptation is a significant but not the primary objective (i.e., that have other primary objectives).

7 In terms of person-months available for the consultant to undertake a CRA.
} 
- For many Type 1 projects, the impacts of climate change on the economic and financial performance of a project will be modest, relative to other factors, especially when the effect of discounting on future adaptation benefits are considered. This includes projects with a short lifetime. For these projects, light-touch CRA approaches should be sufficient.

- For some Type 1 projects, climate change may involve very large risks, and/or could have a material impact on economic and financial performance that may affect the economic internal rate of return (EIRR). ${ }^{8}$ An example might be a large hydropower project. In such a case, a more in-depth CRA and adaptation economic analysis would be justified. Better integration of climate change risks and adaptation within the core design of the project with in-depth assessment is needed: when vulnerability is particularly high, the design should reflect a sound understanding of climate risk management.

19. Adaptation (Type 2) projects were also discussed, but are not the main focus of this paper. These have a primary objective of delivering adaptation and are discussed further in a later section. Projects like these should be identifiable in the concept note and problem tree, as their principal objective will be addressing climate risks.

20. This leads to the second key principle for updating the CRM process.

Principle 2: The type of climate proofing project-and suitability for light-touch assessmentshould be identified early on in the concept phase to ensure that the time and resources required for fit-for-purpose CRA are secured. The lifetime, degree of lock-in, level of precaution needed, and project size should be considered.

21. Its implementation will require some updates to the CRM and the project climate risk screening steps (and approach) to recognize the different project types, as well as to introduce a differentiated approach in the updated CRA guidance. The recommended differentiation for climate proofing (Type 1) projects is as follows:

- Projects suitable for light-touch analysis, with associated light-touch CRA.

- Projects that necessitate a more in-depth assessment because climate risks and opportunities are very material to the project and adaptation needs are high. ${ }^{9}$ These projects will require more resources for the CRA.

22. For climate proofing projects, an initial checklist was developed to help differentiate projects during the early concept stage. The criteria include:

(i) lifetime of the scheme;

(ii) risk of lock-in;

(iii) level of precaution warranted;

(iv) potential economic impact of climate change or adaptation costs (on the EIRR); and

(v) size of the project.

8 ADB uses the EIRR as the primary economic metric for project appraisal (ADB 2017b) with a required minimum rate for investment decisions. The general criterion for accepting a project is its ability to achieve a positive expected net present value (ENPV), discounted at the minimum required EIRR, or to attain the minimum required EIRR.

9 These are not referred to as "high" climate risk projects to avoid confusion with the ranking in CRA screening. 
23. The above criteria can help in deciding whether a climate proofing (Type 1) project can be considered for a light-touch analysis or if an in-depth CRA is required. These criteria are based on the literature (Fankhauser, Smith, and Tol 1999; Ranger et al. 2010; Watkiss and Hunt 2011; Warren et al. 2018), project screening criteria used in assessment guidance (Ray and Brown 2015), ADB guidance on the economic analysis of climate proofing investment projects (ADB, 2015a), and the economic review of climate proofing projects in ADB (Box 1). Type 1 projects are differentiated on the basis of these criteria as follows:

- Projects with a longer operational lifetime are likely to be exposed to greater climate change risks, as climate signals are expected to increase with time (at least within this century). This means the projects may need to consider a greater level of climate proofing, although due to issues of discounting, there is still a need to assess whether this makes economic sense. Conversely, projects with a short lifetime should focus more on present climate variability, rather than future climate change effects. For example, wind turbines have a short operational and economic lifetime (under 20 years) so future climate change risks are likely to be modest. However, a detailed analysis of current weather would clearly be needed. Note that while lifetime is variously defined in the economic, financial and engineering domains, ${ }^{10}$ the focus here is on projects with an operational lifetime of over than 30 years.

- Some investments are extremely difficult or costly to alter retrospectively (retrofit) in later years in response to a changing climate. This means that the projects involve a degree of irreversibility or lock-in. A new major sea bridge, for example, will not be easily raised at a later point in time. There can also be issues of lock-in with land-use change, e.g., urban expansion into areas that could be exposed to high future climate and flood risk. A project with a larger risk of lock-in is likely to require more careful consideration of climate risks and adaptation options, including the possible use of decision-making under uncertainty approaches, which requires more in-depth analysis.

- Some investments already incorporate high levels of precaution to current climate risks, setting higher design criteria to reduce the chance of failure. Examples are large dams and other critical infrastructure. In these cases, there can be major regrets if the investment subsequently fails because of climate change, leading to potentially significant impacts as well as reputational risks. ADB already adopts a more precautionary approach to such investments, choosing to overdesign rather than to go with the optimal design, for example. These investments may warrant a greater level of precaution and a higher degree of climate proofing, but requires more in-depth consideration, especially on costs. Mapping the current ADB portfolio, to assess which projects already take, or might justify, a more precautionary approach would be useful.

- For some projects, the climate risk is large and could significantly affect project economics and the EIRR, ${ }^{11}$ or involve a large increase in the cost of adaptation of the project and the overall financial cost (and, consequently, the loan amount). In such cases, a more in-depth analysis is warranted.

10 The economic and financial appraisal considers the lifetime of projects, but this is different from the design (engineering) lifetime (ADB 2017b). Economic life is defined as the number of years before the annual economic cost of operations starts to exceed annual economic benefits. Project benefits and costs are identified for both the implementation period of major investments and operating years, known as the operating life of projects. The number of operating years to be included in the analysis is usually determined by the technical life of a project, which is the number of years of normal operation before the project fully wears out. However, if the economic life of the project can be estimated and there are indications that this will be significantly shorter than the technical life, the economic life should be used in the analysis. In practice, the financial loan period (typically 25 years) is often used.

11 In most cases, climate change impacts are unlikely to reduce the central EIRR of a project to below the ADB threshold (if the baseline project is viable). Under sensitivity testing, however, climate change could lead to such an outcome. 
- Very large ADB investments (e.g., over $\$ 400$ million) have an element of financial risk from portfolio concentration and risk concentration. It makes sense to consider a greater level of risk aversion for such large investments, especially when exposed to medium to high climate risks.

24. This approach was tested in the CRA pilot studies (Box 2) and found to be a useful way to undertake an initial screening exercise to determine project type and subsequent CRA approach. Examples are shown in Table 1.

\section{Table 1: Examples of Project Suitability Assessment for In-Depth vs. Light-Touch Climate Risk and Adaptation Assessment}

\begin{tabular}{|l|l|l|}
\hline \multicolumn{1}{|c|}{ Type of Project } & \multicolumn{1}{|c|}{ Detailed CRA } & \multicolumn{1}{c|}{ Light-touch CRA } \\
\hline $\begin{array}{l}\text { Type 1. Climate } \\
\text { Proofing } \\
\text { (climate adaptation is } \\
\text { a secondary objective) }\end{array}$ & $\begin{array}{l}\text { New large hydro-electric power plant } \\
\text { and reservoir } \\
\text { (long lifetime, high risk of lock-in, high } \\
\text { level of precaution [safety] required, large } \\
\text { project) }\end{array}$ & $\begin{array}{l}\text { Upgrade of existing road project or } \\
\text { new wind power project } \\
\text { (shorter lifetime, low risk of lock-in, } \\
\text { low level of precaution, small project) }\end{array}$ \\
\hline $\begin{array}{l}\text { Type 2. Adaptation } \\
\text { (climate adaptation } \\
\text { is the principal } \\
\text { objective) }\end{array}$ & $\begin{array}{l}\text { New hard coastal protection to defend } \\
\text { against sea-level rise risks } \\
\text { (principal objective, long lifetime) }\end{array}$ & $\begin{array}{l}\text { Some technical assistance } \\
\text { projects, policy reform, and } \\
\text { resilience financing } \\
\text { (principal objective, but short } \\
\text { lifetime, and focus on enabling } \\
\text { conditions for in-depth adaptation) }\end{array}$ \\
\hline $\begin{array}{l}\text { New building codes or engineering design } \\
\text { standards that incorporate allowances for } \\
\text { climate change } \\
\text { (principal objective, risk of sector lock-in) }\end{array}$ & \\
\hline
\end{tabular}

CRA = climate risk and adaptation assessment.

Note:

a Some non-structural Type 2 projects may not require in-depth CRA. These might include some technical assistance projects, contingency loans for policy reforms to address the barriers to adaptation, resilience financing (e.g., post-extreme event responses), or lines of credit to small and medium-sized enterprises for the development of climate-resilient solutions or services. Source: Author's formulation.

25. The differentiation of projects, and the use of the criteria, should be reflected in the updates to the CRM. This could involve the addition of a new checklist, as part of early CRM steps. It could also be folded into a guidance note on CRAs to advise on the terms of reference of a CRA consultant for a specific project.

26. A number of further issues are highlighted in the update of early steps in the CRM process. First, projects that are identified as climate proofing (Type 1) projects and require in-depth analysis should be clearly flagged, so that these are subjected to more in-depth climate risk and adaptation analysis during the early CRA steps of the concept stage and results of assessment will feed into the subsequent technical design.

27. Second, certain types of projects in the ADB investment portfolio (e.g., hydro-electric power plants) generally have high climate risks, and could be routinely classified as in-depth Type 1 projects. It would be beneficial to identify and map out which projects are likely to require in-depth CRA and highlight these to ADB departments. 
28. Third, for the subsequent preparation step, it would be worth adopting specific CRA guidance for projects that routinely require in-depth CRAs. Other MDBs are already developing separate guidance for high-risk investments. One example is the Hydropower Sector Climate Resilience Guide (IHA 2019) issued by the International Hydropower Association with technical and financial support from the World Bank Group and the European Bank for Reconstruction and Development.

\section{Box 2: Climate Risk and Adaptation Assessment Pilot Studies}

Following the initial trialing of the principles and feedback from the training workshop on climate risk and adaptation assessments, held in Manila on 22-23 November 2018, the new approach was tested with climate risk and adaptation assessments in two large irrigation projects during their preparation phase. The screening criteria mentioned above were tested and were found to successfully differentiate between the two projects. While one scheme was deemed suitable for light-touch CRA, the other was seen to require a more detailed analysis. This was because this scheme had a longer lifetime, it was a larger project, and it had greater investment in fixed infrastructure (more lock-in).

Source: Authors' formulation.

\section{PROJECT PREPARATION PHASE}

29. The next step in the project cycle is the preparation phase. This is when the technical design and the economic appraisal are undertaken. For projects identified during the concept climate risk screening as being at medium or high risk, a CRA is conducted for the project design. ADB has produced guidance for undertaking CRAs. The main work-flow diagram and detailed steps are presented in Figure 3, with the results feeding into the CRA report.

Figure 3: The Climate Risk and Adaptation Assessment Process and the Preparation Phase

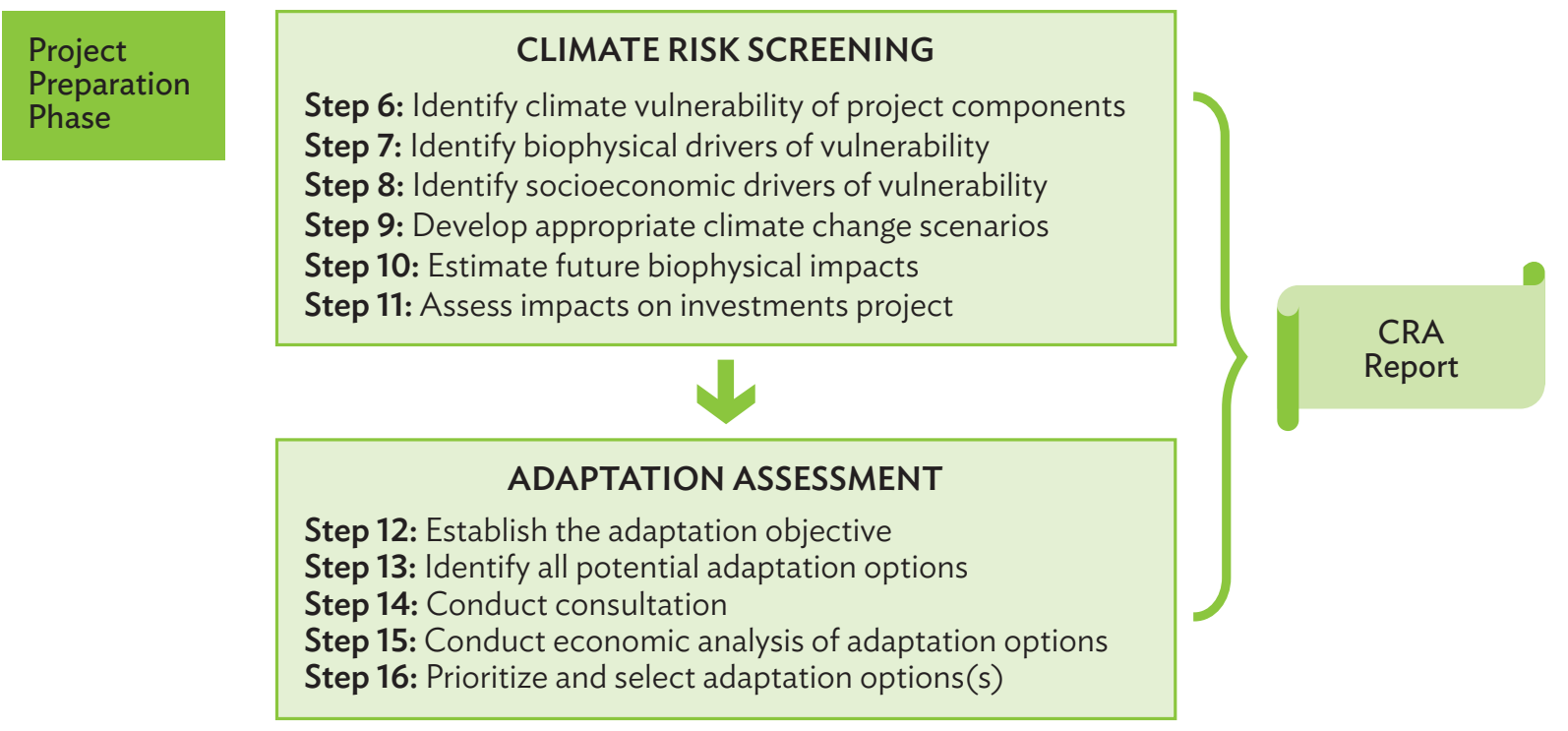

CRA = climate risk and adaptation assessment.

Source: Asian Development Bank (ADB). 2015a. Economic Analysis of Climate-Proofing Investment Projects. Manila. 
30. Following from the principles outlined in the previous section, a differentiated approach to CRA is needed during the concept and preparation phases. This section sets out the relevant principles for different project types, starting with a light-touch climate risk assessment, and where a lighter-touch method is warranted for climate proofing projects.

\section{A. Climate Proofing (Type 1) Projects Suitable for Light-Touch CRA}

\section{Early tasks}

31. The review of existing CRAs ( Box 1 ) identified several issues which were confirmed by workshop participants. Among the most important concern was that most CRAs begin with a very detailed assessment of future climate change scenarios and climate model projections (effectively, step 9 in Figure 3). This makes the CRA very science-first, with focus on the long-term climate model results rather than on risks to project outcomes and adaptation needs. The climate information presented in CRAs tends to focus on average climate metrics, particularly annual mean temperature and precipitation, rather than on metrics with more relevance to the project (e.g., seasonal rainfall change or intense precipitation). This means that the detailed scientific climate information may not be directly relevant for subsequent risk analysis.

32. Recent literature and applied studies have highlighted that this type of science-first approach is generally unhelpful for informing adaptation decisions (e.g., Warren et al. 2018). The recommended approach is to focus instead on the project first, understand the objectives, outputs and outcomes, and assess how the project might be affected by climate risks, i.e., to identify the important impact or risk pathways. This also helps in identifying what subsequent climate information is needed.

33. A useful starting point for the initial steps in the CRA is to start by understanding the project, using the project concept note, and examining the problem tree, objectives, rationale and solutions, as well as the outputs. The result can be useful to map out the pathways through which climate risks could have an effect on these objectives, outputs and outcomes. The recommendation is to begin with current climate risks then move to future climate change.

34. Climate risk screening at the concept phase (the previous stage) is only indicative. The screening phase (including output from the use of the climate screening tool AWARE ${ }^{T M}$ for Projects) may have omitted some potential risks, or may have over emphasized others. Therefore, it can be helpful to revisit the climate risk screening results and consider the potential risks in light of the project concept.

35. The climate risk mapping should recognize the various risk pathways and potential impacts on project outputs. Taking the example of an irrigation project, climate risks may affect both the supply and demand of water, which influence the project design of the infrastructure, but it may also affect crop production, as well as yield and income that the project generates as benefits. All these may be important when considering climate risks and subsequent adaptation assessment, but require different information and analysis.

36. The initial steps of a CRA - and the mapping recommended above-can often identify a very large number of climate risks. A key priority is deciding where to focus or identifying the first-order concerns. It is important to frame this prioritization based on the objectives and outcomes of the project (linked to the discussion above). This early consideration should also identify early adaptation objective(s). ${ }^{12}$

12 While establishing the adaptation objective is step 2 in the existing guidance, consideration of adaptation objectives earlier in the process is recommended. 
37. To do this, it is necessary to understand what is important for the success of the project (i.e., assuming no climate change), including the key outputs and indicators, and then to understand the effects of climate variables (both present variability and future change). This aligns with some of the decision making under uncertainty literature, such as decision-scaling methods ${ }^{13}$ (Ray and Brown 2015), which encourage the identification and analysis of key performance indicators for the project first, and assess the effects of current climate risks, before moving to future climate change.

38. The project concept note and early technical review reports will include some discussion about the key parameters and indicators of a project. Such dialogue provides useful information for identifying what matters. Conversations with the project design team can improve understanding of key aspects of the project, and find out what is important for the project's success. This process may also reveal if there are particular threshold levels which, if exceeded, would affect project performance. These thresholds are used in many adaptation decision methods, such as the dynamic adaptation pathways, which are relevant to adapting infrastructure design for future climate risks (Haasnoot et al. 2013; UNESCO 2018).

39. The scale of current and future climate risks can also be assessed through simple mapping of consequence and likelihood, as shown in the ADB agriculture climate proofing guidance (ADB 2012).

40. ADB appraises investment projects in terms of EIRR as the ultimate key indicator. However, the review (Box 1) pointed out that most CRAs lack strong economic analysis, and this presents an opportunity for improvement. It is, therefore, useful to begin considering the economic risks of climate change to a project at the start of the CRA process, rather than as the final step of the analysis (as in the current guidance, where economic analysis is Step 15; Figure 3).

41. It is recommended to consider how climate change could affect the economic and financial performance of a project in this initial phase. It is possible to scope out how the present and future climate could affect assets, operation and maintenance costs, as well as revenues or benefit streams, as highlighted in Table 2 below.

42. The output of this initial step might be a list of key (first order) issues for the main climate risk assessment to focus on, i.e., the top five key risks that could have a material impact on the project and warrant further consideration. These risks, and the reasons for their selection, should be documented. The discussion above leads to the following principle for updating the CRM process.

Principle 3: The CRA should begin by focusing on what matters: understanding key climate risks that can affect the project objectives and outcomes. Climate projections come later.

13 The decision-scaling method starts with the identification of the performance indicators for the project. Acceptable thresholds for those indicators are assessed to determine the effects of current conditions and future climate change. 
Table 2: Economic Categories for Climate Change Risk Assessment

\begin{tabular}{|c|c|c|}
\hline Category & Current Weather and Extremes & Future Climate Change \\
\hline Asset/Capital cost & \multirow{5}{*}{$\begin{array}{l}\text { - Assess risk of current climate } \\
\text { variability and current weather } \\
\text { extremes (e.g., shocks such as } \\
\text { floods) for categories shown in } \\
\text { the first column } \\
\text { - Assess whether any risks could } \\
\text { affect the financial or economic } \\
\text { performance thresholds of the } \\
\text { project }\end{array}$} & \multirow{5}{*}{$\begin{array}{l}\text { - Assess the risks of slow-onset } \\
\text { change for categories shown in } \\
\text { the first column } \\
\text { - Assess potential risks of } \\
\text { changes in the intensity, } \\
\text { duration, or frequency of } \\
\text { extreme events and changes in } \\
\text { variability for the categories } \\
\text { - Assess whether any risks } \\
\text { could affect the financial } \\
\text { or economic performance } \\
\text { thresholds of the project }\end{array}$} \\
\hline O\&M/O\&M costs & & \\
\hline Revenues/Benefit stream & & \\
\hline Access to finance/Insurance & & \\
\hline Socioeconomic effects & & \\
\hline
\end{tabular}

O\&M = operation and maintenance.

Source: Watkiss, Paul. 2018. Strengthening Adaptation Economics in the Asian Development Bank. Report submitted to the Asian Development Bank. Manila.

43. At this early stage in the analysis, it is also critical to define the adaptation objective(s). The aim is to establish the risk that climate change poses to the achievement of the project objective and outcomes. It should also consider if the project could increase the vulnerability of the surrounding area and population. While this process is already included in the existing CRM guidance (e.g., ADB 2015), the proposal is to undertake it earlier-even before the climate risk analysis starts. This step considers each identified key risk and assesses the type of adaptation needed in response. It is also recommended that possible adaptation decision(s) be identified. It should be noted that criteria for assessing projects in the concept phase (para. 22) are also useful when framing the adaptation objective (i.e., lifetime, period of interest, level of irreversibility or lock-in, importance of uncertainty, and level of precaution that might be warranted).

\section{Undertaking the climate risk assessment}

44. The next step in the CRA process is the main analysis of climate risks. For light-touch CRA, once the climate risk pathways and priority risks have been identified (as above), the analysis of climate information and climate model projections can then be considered.

45. The review of previous CRAs (Box 1 ) and feedback from the workshop offer valuable lessons for the risk assessment phase. Some CRAs that were reviewed had performed detailed risk assessment using impact models, but these often focused on later time periods (e.g., beyond 2050) and made very detailed use of a single-impact model (e.g., a crop or hydrological model), instead of looking at a suite of risks and focusing on how climate risks would affect the actual project over its planned lifetime. Several CRAs that were reviewed contained detailed analyses of future climate model output and failed to focus on key risks (e.g., providing detailed plots and tables for average temperature and precipitation change rather than the specific risk metrics of relevance to the project). For example, irrigation projects are often designed to meet the 10-day peak demand, with an allowance to cope with inter-annual variability (for a 1-in-5 dry year). It is important to consider how climate change might affect this design, while at the same time taking note of annual average rainfall data (e.g., for storage projects or groundwater recharge). 
46. Therefore, the recommendation for updating CRAs for Type 1 light-touch projects is to target risk assessment at key concerns (as identified in the foregoing step) and key areas where adaptation might be needed, and to use rapid risk assessment rather than detailed impact models. This leads to the next key principle for updating the CRM process.

Principle 4: The project risk management context should determine the selection and use of climate information i.e., this should be "decision-led".

47. This type of rapid risk assessment can be done in various ways. The first and simplest approach is for the CRA team to work with ADB project team and the TRTA consultants to identify climate change factors for sensitivity testing in the main project models. Examples of light-touch CRAs can be found in Box 3 .

\section{Box 3: Light-Touch Case Studies and Rapid Risk Assessment}

Within the light-touch climate risk and adaptation assessment (CRA) case studies, a number of approaches were used to undertake rapid risk assessments, in this case for irrigation projects. The potential increase in crop evapotranspiration was estimated via a simple rule of thumb approach, using the Blaney-Criddle (1950) equation. The ADB compendium of information sources (2018b) provided input for the analysis. This provided rapid results, which suggested that climate change might lead to an increase in crop evapotranspiration of about $5 \%$ by mid-century (across the project lifetime), and examined the uncertainty range. The analysis also indicated a small increase in crop water demand, which fell within the existing design tolerance of the scheme.

Similarly, to determine the potential effects of climate change on groundwater recharge and water abstraction potential for the scheme, the light-touch CRA produced change factors that highlighted the relevant seasonal change in precipitation from the climate models. This data was later fed into a groundwater model run by the transaction technical assistance team and allowed the design team to assess whether the full envelope of climate change projections might lead to a drop below sustainable recharge levels.

A third light-touch example was also undertaken on the irrigation schemes, this time looking at extreme heat and the potential effect of Wet Bulb Globe Temperature (WBGT, which is the combination of temperature and humidity) on labor capacity and work intensity. This allowed exploration of a new risk (one that was not picked up in the initial climate risk screening), using local monthly climate data. In this case, potentially high risks to labor capacity were identified for one irrigation project (but not the other), which led to a more in-depth analysis for the vulnerable site.

Sources: Asian Development Bank (ADB). 2018b. Information Sources to Support ADB Climate Risk Assessments and Management: Technical

Note. Manila; Authors' formulation.

48. The second approach is to use simple rules-of-thumb (also known as "ready reckoners") that can provide a sense of the scale of risk involved. These can be used to test the level of risk on the project, and thus whether climate change will impact (and by how much) on key project outputs or performance indicators. Another example of a CRA light-touch case study is included in Box 3. It would be useful to develop a library of response functions and ready reckoners to support light-touch CRAs, with worked examples. This could be used alongside the ADB compendium of information sources (2018b). 
49. Both of these approaches were tested in the pilot CRA projects and demonstrated the value of the rapid analysis of risks. However, this does require a closer level of engagement between the CRA and the core TRTA teams, and it is important to match the timing so that relevant climate information is passed to the TRTA team in line with the work plan. There is also an important role for the CRA team to help with the interpretation of the resulting climate risk analysis for the TRTA team.

50. Irrespective of the approach at this stage of analysis, the results of the climate risk analysis should be used to undertake sensitivity testing in the economic analysis of the project, i.e., to understand how important climate factors might be on the EIRR. One way this can be undertaken is by engaging the economic analysts in the TRTA team to identify change factors (from the rapid assessment) to test the potential impact of climate change on the key economic parameters for the project.

51. More importantly, it is the rapid risk assessment that dictates the climate information that is needed, i.e., it is useful to know which climate parameters are required first. There are good practice recommendations on what type of climate information to use and how to source this.

52. A good practice is to start with the present, and then look to the future. The starting point is to identify historic (observational) local meteorological data. In some cases, this will have already been sourced by the consultants in the TRTA team. However, these local data maybe missing, difficult or costly to obtain, or of poor quality. The ADB compendium of information sources for climate risk assessments and management (ADB 2018b) provides open access sources that can be used to derive relevant data. This should include an analysis of the observerational baseline data using relevant metrics and analysis of observed recent meteorological trends. The results often show changes that can provide greater confidence in the direction of future climate change over the short to medium term. ${ }^{14}$

53. For the analysis of future climate change information, the main focus is most likely to be on change factors. These can then be applied to baseline data-ideally to the observational baseline data, rather than modeled baseline-rather than use of absolute climate model values (i.e., it is the change in temperature, measured as the difference between the baseline model simulation and the future period, that should be used). Again, the ADB compendium of information sources (2018b) sets out the possible information sources for future climate change information. While the guidance does not prescribe the exact use of future climate scenarios and model output, it highlights a number of good-practice issues:

- It is important to match the time periods for future climate change to project lifetime. This is likely to mean a greater focus on the mid-century rather than late-century. It is not good practice to consider only central (average) projections or only the worst case: the consideration of uncertainty is important. It is good practice to reflect both the future emission scenario (considering alternative representative concentration pathways) and the climate model uncertainty for these pathways (considering different models in an ensemble, but looking at the ensemble range).

54. In the future, it may be useful for ADB to produce guidance on the choice of scenarios and models, including uncertainty sampling.

55. The results from this stage will provide information about the level of risks that will form the basis for the adaptation assessment. These principles and changes in the CRA for light-touch projects are recommended as part of the CRM and CRA guidance update, and the supporting terms of reference for CRA consultants. Looking forward, there will be further opportunities to develop a compendium on

14 It is noted that alongside climate trends and climate information, the CRA will need to consider socio-economic data and trends, although much of these data should be collated by the core technical team as part of the design and feasibility studies. 
rapid assessment, to look at sector-specific guidance, and to move toward sector-wide TRTA facilities that might enhance an integrated approach to CRAs.

\section{Undertaking the adaptation assessment}

56. The next step in the CRA process is adaptation analysis. The first task in the existing guidance (Figure 3, step 12) is to identify the adaptation objective. As pointed out earlier, the adaptation objective should be identified early in the overall CRA process, before the quantitative risk assessment begins, largely because the climate risk information should inform the adaptation decision. However, it is important to check and precisely define the adaptation objective at this point in the CRA analysis, based on the results of the climate risk assessment.

57. In order to inform the adaptation objective, it is important to consider the type of adaptation characteristics that are associated with the project, and in particular, the relevant characteristics of its lifetime, the level of lock-in, and the level of precaution (as identified in para. 22). In many cases, there may be more than one adaptation decision associated with a project, or there may be the need for an integrated analysis of adaptation. This could relate to multiple components of a project with different lifetimes or lock-in characteristics, such as the longer lifetime and higher lock-in associated with bridges within an overall road project. It could also relate to different components of a project associated with capital investment as compared to long-term operations (e.g., the service contract for the longterm management and farmer extension services for a major irrigation project, as well as the capital infrastructure investment).

58. The next task (Figure 3) is to consider all possible adaptation options. This is important as it recognizes that there are alternative adaptation choices for addressing climate risks. In general, it is not good practice to over-design (or over-engineer) a project to cope with any possible level of future climate change, as this is likely to be a more expensive option, and given uncertainty, this level of investment may not be needed. But there may be exceptions, such as when a high level of precaution is warranted or if over-design involves very low incremental costs. ${ }^{15}$

59. The range of adaptation options considered should include both technical and engineering options (sometimes called "hard adaptation") and nontechnical options (sometimes called "soft adaptation"). Alternative ways of risk management, such as reducing risk by spreading the residual risk (insurance) or other measures, should likewise be looked into. Doing nothing (living with the risk) is also an option.

60. The CRA review (Box 1) identified several issues with previous assessments. In some cases, the analysis of adaptation was very generic, offering broad suggestions rather than firm options. In other cases, there was an over reliance on technical (engineered) options usually based on the worst-case climate scenario (over-design). Important additional feedback from the workshop participants underscored the difficulty in costing and prioritizing adaptation (Figure 3, steps 15 and 16).

61. This finding was borne out by the economic review (Box 1). It identified that selecting suitable adaptation options for investment projects (especially in relation to infrastructure) is challenging for a number of reasons (OECD 2015). First, it is it very difficult to decide how much adaptation to build into a project when designing at the present time, because the future risks of climate change are uncertain as shown by the wide range of future changes projected across different scenarios and climate models. Second, making a strong economic case for adaptation is often difficult, because climate change is

15 While designing for worst-case scenarios is not economically effective in many cases, it can be useful to have a plan should such conditions materialize, i.e., to strengthen emergency planning. 
gradual and larger impacts (and, therefore, larger adaptation benefits) only arise in the future. These are therefore low in present value terms (in an economic analysis) when compared with the up-front adaptation costs incurred during project construction. ${ }^{16}$ These two issues combine to make adaptation investment difficult, i.e., adaptation can increase project costs, but provides uncertain benefits in the distant future which may subsequently turn out to be unnecessary.

62. Existing ADB guidance on the economics of climate proofing (ADB 2015a) recognizes these challenges and suggests ways of addressing these using detailed economic analysis (Box 4). Similar approaches have emerged in the adaptation literature, with a suite of decision making under uncertainty (DMUU) approaches (Watkiss et al. 2015). These DMUU methods use principles such as robustness, diversity, flexibility, learning, and choice editing to help in selecting adaptation options that work well under uncertainty. Various decision support tools, such as robust decision making, adaptive management, dynamic adaptation pathways, real options analysis, and portfolio analysis have also emerged.

63. However, the review of existing CRAs and workshop feedback found that teams had struggled to implement detailed economic analysis and apply this set of criteria for prioritization. Furthermore, the economic review (Box 1) noted process and governance barriers to implementing detailed economic analysis of adaptation in ADB, especially the quantitative approach set out in Box 4 below. This is because the focus in ADB is on EIRR analysis rather than the appraisal of economic options. The economic analysis happens toward the end of the assessment phase, when the design of the project is already largely settled (and thus, too late to change design).

64. Therefore, a recommendation is that the CRA update also needs to provide guidance for light-touch approaches for the analysis and prioritization of adaptation, including the economic analysis of adaptation.

65. Two aspects are noted for the CRA update. First, it is useful to build on existing climate proofing sector guidance, which involves identification of potential types of adaptation for addressing climate risks (technical or non-technical, reduce risks directly or use alternatives, etc.). ADB guidelines for climate proofing investment in the energy sector (ADB 2013c) offers an example where adaptation options are presented by sub-area by risks. ADB is also preparing an updated set of adaptation options and support information by sector. Second, it is useful to consider the existing ADB economic report on climate proofing, and consider the timing of adaptation and the importance of uncertainty-whether to act now or later-but with a lighter-touch approach. To support this, a table was developed to help guide teams, which was refined during the pilot studies (Table 3).

16 Discounting is influential for climate change because the use of high discount rates reduces the importance of future longterm damage and leads to lower economic costs when expressed in currentvalues (Watkiss 2011). As a result, the choice of discount rate has been the subject of debate in the global mitigation literature, largely because of intergenerational impact. However, for climate proofing (Type 1) projects, the discount rate associated with the underlying investment should be used, otherwise there would be different rates for different project components. Type 2 projects and strategic resilience investments may involve intergenerational issues. Further discussion within ADB of appropriate discount rates/EIRR thresholds for these projects is recommended. 


\section{Box 4: Economic Analysis of Climate Proofing Investment Projects}

The Asian Development Bank has produced a targeted report to inform the economic analysis of adaptation for climate proofing projects. It sets out that the economic analysis of climate proofing investment projects does not differ from the guiding the analysis of any other investment project, and should therefore follow ADB's guidance on the use of economics (ADB 2017b). However, the guidance recognizes that the presence of uncertainty does require a different type of decision-making process to present decision makers with information about the economic efficiency of investment projects in the context of a changing climate, and of investments in climate proofing options.

The report identifies a series of questions to help guide this discussion, along with suggestions for the economic analysis. It also recommends that the outcome may result in three different types of decisions:

- climate-proof now (in the initial design);

- make the project climate-ready; or

- wait, observe, collect information and data, and revise if and when needed.

The report also sets out the conditions that could influence these decisions. For example, the decision to climate proof now might be taken if there are immediate economic benefits (no-regret action, which reduces the impact of current climate variability), or if the costs of climate proofing are small or the future benefits are large. It might also be relevant if climate proofing later is not possible (because of irreversibility or high costs). Conversely, if these factors are not present, then either of the two other options might be a more appropriate choice.

Sources: Asian Development Bank (ADB). 2017b. Guidelines for the Economic Analysis of Projects. Manila; authors' formulation.

66. This framework can help identify promising adaptation options for inclusion in the projectoptions that are likely to have economic benefits (including avoiding potential losses), while taking uncertainty and discounting into account. These options are based on the literature and types of early adaptation priorities (e.g., Warren et al 2018):

- Addressing the current adaptation deficit by implementing "no-regret" or "low-regret" actions, ${ }^{17}$ to reduce risks associated with current climate variability as well as build future climate resilience.

- Intervening to ensure that adaptation is considered in near-term decisions that have long lifetimes, such as major infrastructure developments. This will avoid lock-in, with climate-smart design using decision making under uncertainty (DMUU) concepts.

- Fast-tracking early adaptive management activities, especially for decisions that have long lead times or involve major future change, including planning, monitoring, and research. This can be used for learning to improve future decisions.

17 No-regret adaptation options are defined as options that "generate net social and/or economic benefits irrespective of whether or not anthropogenic climate change occurs" (IPCC 2007). A variant of no-regret options is win-win options, which are options with positive co-benefits, including wider social, environmental, or ancillary benefits. These are differentiated from low-regret options, which may have low costs or high benefits, or low levels of regret, or which have high economic benefits in relation to costs, but lower financial benefits relative to costs (because of the presence of non-market benefits, or of opportunity or transaction costs). 
Table 3: Adaptation Type, Timing, and Economic Rationale

\begin{tabular}{|c|c|c|}
\hline $\begin{array}{l}\text { Adaptation Type } \\
\text { and Timing }\end{array}$ & $\begin{array}{l}\text { Examples of the } \\
\text { Adaptation Type }\end{array}$ & $\begin{array}{l}\text { Economic Rationale } \\
\text { for Choice of Adaptation }\end{array}$ \\
\hline \multirow{3}{*}{$\begin{array}{l}\text { Design and } \\
\text { engineering for } \\
\text { decision NOW }\end{array}$} & Site or location change & \multirow{3}{*}{$\begin{array}{l}\text { Possible choice from: } \\
\text { - No-regret/Win-win - economic benefits } \\
\text { even without climate change } \\
\text { - Low-regret - low-cost or cost-effective } \\
\text { - Shorter design lifetime to include climate } \\
\text { in future cycles } \\
\text { - Robust project - alter now to perform well } \\
\text { over range of future uncertainty } \\
\text { - Precautionary over-design if needed } \\
\text { (critical infrastructure) }\end{array}$} \\
\hline & $\begin{array}{l}\text { Design change } \\
\text { (engineering) }\end{array}$ & \\
\hline & $\begin{array}{l}\text { Includes dimensions, } \\
\text { materials, technology, } \\
\text { structural considerations } \\
\text { (defenses) }\end{array}$ & \\
\hline \multirow{2}{*}{$\begin{array}{l}\text { Design and } \\
\text { engineering for } \\
\text { climate change LATER }\end{array}$} & $\begin{array}{l}\text { Flexibility built into the } \\
\text { design }\end{array}$ & Flexible design to allow easier upgrade later \\
\hline & $\begin{array}{l}\text { Modular or iterative design } \\
\text { to enable later change }\end{array}$ & $\begin{array}{l}\text { Iterative design to monitor and learn - } \\
\text { upgrade later if needed }\end{array}$ \\
\hline $\begin{array}{l}\text { Maintenance and } \\
\text { operations }\end{array}$ & $\begin{array}{l}\text { Change in maintenance } \\
\text { regime or infrastructure } \\
\text { operations (on-site, } \\
\text { system) }\end{array}$ & $\begin{array}{l}\text { Focus on: } \\
\text { - No-regret or win-win } \\
\text { - Low-regret }\end{array}$ \\
\hline \multirow{3}{*}{$\begin{array}{l}\text { Nontechnical and } \\
\text { nonengineering } \\
\text { options } \\
\text { (alternatives to design } \\
\text { changes) }\end{array}$} & $\begin{array}{l}\text { Institutional and capacity- } \\
\text { building measures }\end{array}$ & \multirow{5}{*}{$\begin{array}{l}\text { Focus on: } \\
\text { - No-regret or win-win } \\
\text { - Low-regret }\end{array}$} \\
\hline & $\begin{array}{l}\text { Includes information, } \\
\text { research, and behavioral } \\
\text { change }\end{array}$ & \\
\hline & $\begin{array}{l}\text { Nontechnical options or } \\
\text { measures }\end{array}$ & \\
\hline \multirow[t]{2}{*}{$\begin{array}{l}\text { Can include accessing } \\
\text { new opportunities as } \\
\text { well as addressing risks }\end{array}$} & $\begin{array}{l}\text { Financial- and market- } \\
\text { based measures (including } \\
\text { insurance) }\end{array}$ & \\
\hline & $\begin{array}{l}\text { Policy and legislative } \\
\text { measures }\end{array}$ & \\
\hline Option to do nothing & $\begin{array}{l}\text { No adaptation (live with } \\
\text { the risks) }\end{array}$ & $\begin{array}{l}\text { If risks and benefits are low, or costs of } \\
\text { adaptation very high }\end{array}$ \\
\hline $\begin{array}{l}\text { Option to reconsider } \\
\text { the project }\end{array}$ & & $\begin{array}{l}\text { If risks are unacceptable and no suitable } \\
\text { adaptation is achievable/justifiable }\end{array}$ \\
\hline
\end{tabular}

Source: Authors' formulation. 
67. For an individual project, there may be a focus on one or another adaptation type, but there will often be a need for a portfolio of responses, either because of different risks with different characteristics, or for an overall strategy that can evolve over time. Some irrigation CRA case studies, for example, made use of a mix of low-regret options associated with farmer extension services, complemented with climate proofing of infrastructure investment and strengthened monitoring to enable a more adaptive management approach to emerging risks (from extreme heat and drought). This discussion leads to the first adaptation principle for updating the CRA guidance for light-touch climate proofing projects (Principle 5a):

Principle 5a (for light-touch CRAs): Early adaptation options should be identified, given the timing and the degree of uncertainty. These should focus on early no- and low-regret adaptation.

68. One way to implement this approach is to identify the adaptation decisions that are needed and their characteristics - and to use this to filter down the likely adaptation choices involved in a particular decision. This approach links back to the balance of risks between the current and the longer-term, and the lifetime of the project (para. 22). It also relates to whether there are characteristics of lock-in or a high level of precaution that requires more focus on early actions for longer-term climate risks. For example:

- If the project lifetime is short, then there is no need for iterative or flexible design. The focus should be on immediate options (technical or non-technical) that are no- or low-regret. These are likely to be options that are very low-cost to design into a project, or options that lead to benefits in reducing the risks of current climate variability and extremes, which would also have benefits under future climate change.

- In contrast, if the lifetime is long or there is potential for lock-in (irreversibility), iterative, robust, and flexible options could be more important and should be considered.

- If there are existing reasons to take a highly precautionary approach-major downside risks in getting things wrong (such as those arising from a major storage dam failure)-over-design options might be warranted, although looking into the availability of lower-cost alternatives for addressing risks would still be useful.

69. For example, the lifetime for a simple upgrade of an existing road is relatively short and there is little lock-in. This would therefore suggest a focus on low-regret and least-cost adaptation (e.g., low-cost over-design of drainage to cope with higher flows). In contrast, the long lifetime and the potential for lock-in (irreversibility) associated with a new port project highlight the need to consider robust, flexible, or adaptive management approaches to its design (Box 4).

70. These suggestions were tested in some pilot CRA studies (Box 5) and useful lessons were brought out. The projects considered had several elements, including an infrastructure component, and service contracts for management and operation and for technical assistance and support. These pertained to different aspects of the project related to various risks, and involved different types of adaptation (both hard and soft options). This underlines the need to understand the project and consider a portfolio of adaptation measures. 
Box 5: Light-Touch Climate Risk and Adaptation Assessment Case Studies

The pilot Climate Risk and Adaptation Assessment (CRA) study undertook a light-touch CRA of an irrigation project that is developing groundwater-fed irrigation project, as well as a number of small riverfed irrigation projects. It included investment in irrigation infrastructure, a long-term management and operation component, and a farmer extension service contract. The pilot CRA study identified key climate risks and undertook a rapid risk assessment (Box 3). It then advanced a light-touch analysis of adaptation. To do this, the study took each of project components and assessed the potential adaptation decisions involved, matching these to identified climate risks. It assessed the lifetime of the irrigation infrastructure and management components (using design handbooks), as well as the potential for lock-in. The study analyzed the economic case for the project, which found benefits were driven by farm-level productivity improvements.

This led to a focus on no- and low-regret adaptation options that would not only enhance the resilience of infrastructure but also maintain farm revenues under a changing climate, including additional actions to monitor and prepare for extremes (shocks) in the future. These interventions have high immediate benefits for the project, and also build resilience for the future. A set of low-regret options were recommended for the infrastructure investment, around site choice and low-cost over-design for critical infrastructure components (e.g., raising the height of critical electrical equipment for the pumping house and sub-stations; relocating to an area that was below a flood embankment; making sure higher temperature rating was factored into cooling components). The CRA also recommended options for climate-smart extension services, to help farmers respond to the changing climate (through improved soil and water management, integrated pest management, etc.), including enhanced weather and climate services (from early warning to seasonal forecasts). It included the addition of climate risk management activities and enhanced efficiency in the irrigation operator management and operation agreement, as well as emergency response plans for extreme weather events (floods and droughts). The CRA pilot also identified possible infrastructure investment options that could increase resilience in the project, focusing on options that enhanced flexibility to scale-up in the future, as well as opportunities to strengthen resilience through upgrades as part of the planned cycle of refurbishment.

Finally, given that the project would operate over a period of potentially major climate change (from 2030 onward), but around which there is high uncertainty, the CRA pilot study recommended an adaptive management component, to observe and monitor, learn and improve adaptation over time. This component included in-field meteorological stations, and enhanced monitoring (e.g., of crop productivity, pests and disease) and assessment (e.g., of changing crop suitability) to help improve irrigation operation and farmer responses to the changing climate.

The CRA review work has also identified other light-touch CRAs in the Asian Development Bank portfolio. These provide additional case study material. Example include the pre-feasiblity study for Vanuatu and the Tuvalu Outer Island Maritime Infrastructure Project (48484-001).

Source: Authors' formulation.

71. To help enhance the analysis of adaptation in CRAs, ADB funded studies on technologies supporting climate change adaptation in developing Asia (ADB 2014d), which produced valuable information for early options analysis. ADB is also preparing guidance on adaptation options, by sector, to be published shortly. For this purpose, it has developed an inventory of adaptation options for a range of climate risks in five key sectors. Options being evaluated take into account a number of criteria, including costs and technical requirements for implementation. It must also be emphasized here that adaptation often involves more than technical options. There can also be policy and regulatory barriers to adaptation. Projects can carry out activities that help address these barriers and strengthen the enabling environment for climate proofing, although these may require actions at the national level. An example from Viet Nam is presented in Box 6. 


\section{Box 6: Policy and Regulatory Interventions}

There can be institutional or policy barriers to building climate resilience into infrastructure projects. One example is in engineering standards. Many countries have national design standards, building codes, etc., that set mandatory safety and performance criteria for new investments. However, these are typically based on historic weather extremes and do not take the changing climate into account. These standards can act as barriers to climate proofing, as exceeding these specifications (with higher levels of resilience) is not required under existing national performance criteria and adds to costs. These obstacles can be addressed by working with countries to update their building codes and engineering design parameters, to account for changes in the characteristics of design extreme weather events (Wilby and Keenan 2012). The Asian Development Bank has been taking such initiatives forward. For example, during the project preparation phase for the Basic Infrastructure for Inclusive Growth in the Northeastern Provinces Sector Project in Viet Nam, work was done to adjust the road design parameters to account for changes in 1-in-25-year extreme rainfall events in the future (ADB 2017c). In line with the relevant government regulations governing the road design standards (e.g., for category 4 rural roads, 1-in-25-year extreme rainfall is defined as the design frequency, and a set of formulas is specified for hydrologic calculations), analyses were made to estimate the engineering design parameters under future climate conditions (ADB 2018a). These enabled the updating and adjustment of the design parameters for the national design standard in a changing climate. The analyses translated climate model projections of future climate into climate "safety margins" for standard variables such as heavy precipitation, sea-level rise, and river flow. Case studies have also been developed as part of a knowledge product (ADB 2020) to show step by step how this approach can be applied in practice. This approach allows the use of light-touch climate proofing under the overall project and subsequent road investment projects in Viet Nam.

\section{Adjusting Hydrological Input for Road Design for Climate Change Based on Extreme Value Analysis}

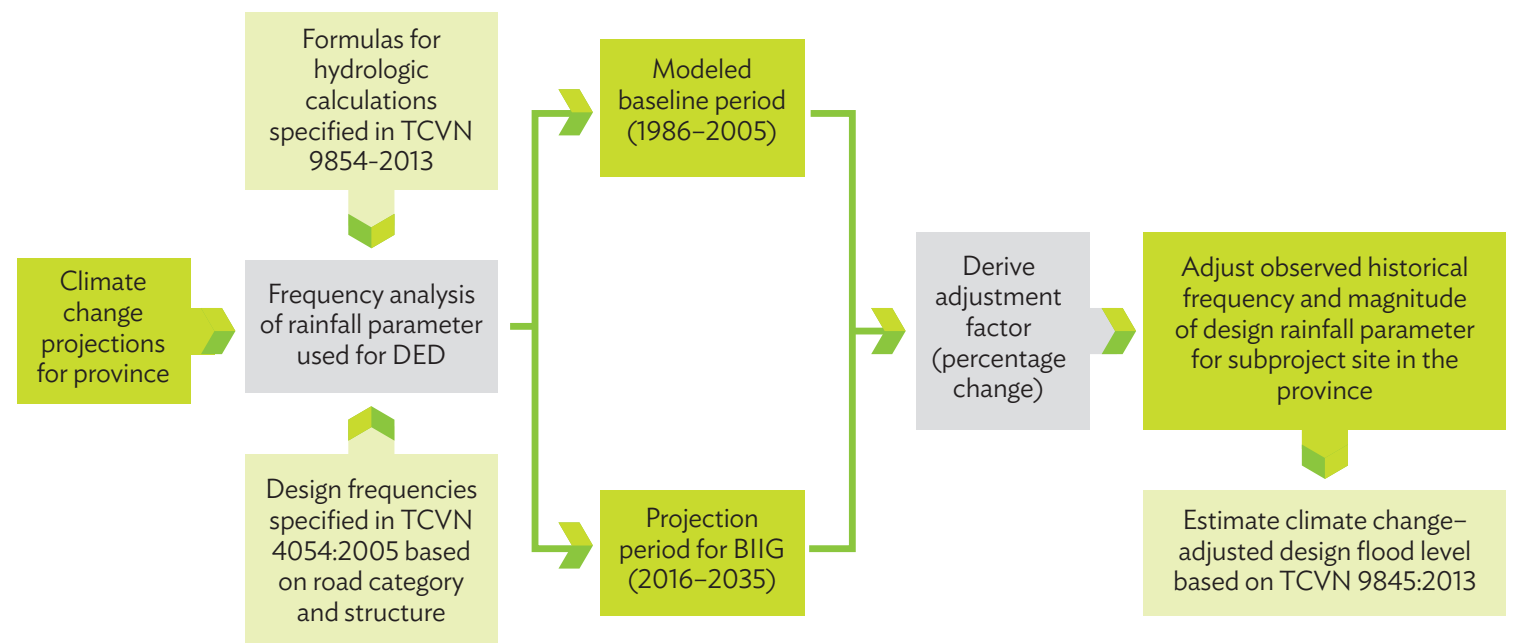

BIIG = Basic Infrastructure for Inclusive Growth (project), DED = detailed engineering design, TCVN = Technical Committee of Viet Nam.

Sources: Asian Development Bank (ADB). 2017c. Report and Recommendation of the President to the Board of Directors: Proposed Loan to the Socialist Republic of Viet Nam for the Basic Infrastructure for Inclusive Growth in the Northeastern Provinces Sector Project. Manila; Asian Development Bank (ADB). 2018a. Adjusting Hydrological Inputs to Road Design for Climate Change Risk Based on Extreme Value Analysis. Manila (TA 8957-VIE); Asian Development Bank (ADB). 2020. Climate Change Adjustments for Detailed Engineering Design with Worked Examples from Viet Nam. Manila; Wilby, Robert L., and Rod Keenan. 2012. Adapting to Flood Risk under Climate Change. Progress in Physical Geography. 36 (3). pp. 348-378. ISSN: 0309-1333. DOI: 10.1177/0309133312438908; authors' formulation. 
72. An inventory of good-practice adaptation options (in terms of type, timing, and rationale) is expected to emerge over time for particular investment project types (e.g., for road projects). This will enhance the potential for light-touch methods.

73. Finally, the CRA pilots provided additional information on undertaking an economic analysis of adaptation for a light-touch climate proofing (Type 1) project. As highlighted earlier, it is challenging to do this in detail (Box 4), especially given the likely time and resources available. The workshop identified it is easier for teams to identify incremental costs than to estimate adaptation benefits. A pragmatic approach is to use an economic rationale (Table 3, Economic Rationale for Choice of Adaptation) to filter down promising options with high adaptation benefits and to focus on no- and low-regret options or low-cost options. This can use information from previous projects (in the portfolio) alongside external resources (for example, the ECONADAPT [2017] inventory and look-up tables). It can also be helped by talking with project teams to identify promising options (Box 5), and using sensitivity analysis (from the CRA team) with the existing TRTA economic analysis, as well as the ADB economics division. Over time, sector and regional teams will be able to build up information on costs, allow light-touch approaches e.g., with cost estimates and cost benchmarks, and improve information on economic benefits. The economic review (Box 1) also sets out suggestions for improving the economics of adaptation for light-touch project, thus highlighting the need for targeted support material light-touch projects. This includes information for common project investment types, lookup tables (including benchmarking costs, and indicative economic benefit estimates), and good practice case studies, complemented with staff training on climate economics (both in the economics and regional divisions). It is emphasized that as a first step, it would be useful to develop a set of economic light-touch examples for a selection of common project types across ADB.

\section{B. Climate Proofing (Type 1) Projects Requiring In-Depth CRA}

74. Principles 3, 4 and 5 are also broadly relevant to more detailed climate proofing projects, where climate risks and opportunities are highly material to the project. There are minor differences, however. Principle 3 is recommended for more in-depth climate proofing projects. In such projects, it is even more important to start by understanding the project, assessing how climate risks could affect project objectives and outcomes, and defining the adaptation objectives early on. The focus on the use of decision-led climate information (Principle 4) is highly relevant as well, although this has to be applied in the context of more detailed climate risk analysis, rather than a light-touch assessment. For in-depth CRAs, it will usually be necessary to undertake more detailed modeling of climate risks, focused on key indicators, and to work in close collaboration with the TRTA team. Principle 5 is also applicable to more detailed climate proofing projects.

75. The general approach of identifying options that show early promise, and taking uncertainty and economic rationale into account, still applies. However, when major design changes are involved, a greater focus on decision making under uncertainty may be warranted. This means that a more indepth analysis of climate risks and adaptation options will be justified. This analysis would include a more detailed study of the economic costs and benefits of climate proofing, to reflect the material costs potentially involved. Several good-practice case studies that demonstrate detailed climate proofing of projects are presented in Box 7. The potential development of more customized CRA guidance for specific in-depth Type 1 investment projects is also recommended. This is already starting to happen, with the International Hydropower Association issuing the Hydropower Sector Climate Resilience Guide in 2019. Similar guidance for climate change adaptation for ports and inland waterways is being developed by the World Association for Waterborne Transport Infrastructure, or PIANC (Working Group 178). Other sectors would benefit from initiatives of this kind, along with ADB good-practice examples. 


\section{Box 7: Case Studies on In-Depth Climate Proofing Projects}

There are good-practice examples of climate risk and adaptation assessments (CRAs) that carry out more in-depth analysis. Some of these are discussed below.

The Central Mekong Delta Region Connectivity Project (ADB 2013d, 2014b) was an $\$ 860$ million investment. The ADB supported project aimed at enhancing connectivity between the agricultural and agro-processing provinces of southern Viet Nam and major national and regional markets. The project included the construction of two major bridges (Cao Lanh and Van Cong) across the Mekong River and a 15-kilometer connector road. A study was done to assess the vulnerability of the project to climate change (in particular, to rising sea levels) and to examine climate proofing options. The embankments of the connector road were found to be vulnerable to a projected increase in the frequency and intensity of flooding worsened by the rise in sea level. A resilience project design feature recommended on the basis of these findings was to raise the current design height of the road embankment by an extra 0.6 meters in response to changes in the intensity of the 1-in-100-year flood event under a changing climate (ICEM 2012).

ADB also financed a $\$ 25$ million project that rehabilitated and expanded the Avatiu port in the Cook Islands. Under the project, the harbor entrance was widened, dredging was done to increase the depth of the port, and the ship-turning area was enlarged. In addition, the quay was rebuilt and realigned, and the adjacent wharf deck underwent repair. Following the climate risk screening, the project design was modified to take future climate change into account. To climate-proof the wharf, the existing structure, which was extremely vulnerable to wave action and forces, was replaced with one that had a more flexible design. The works involved strengthening the pilings during construction to increase load-bearing capacity, allowing the wharf to be raised more easily in the future, if the rising sea levels so require (ADB 2008).

The ADB-commissioned CRA review identified other in-depth CRAs in the ADB portfolio, which provided additional case-study material. Among these were:

- Water Efficiency Improvement in Drought-Affected Provinces of Viet Nam. The CRA report will also be developed as a knowledge product.

- The Nam Ngiep hydropower project in the Lao People's Democratic Republic.

- The Khulna Water Supply Project in Bangladesh. While no formal CRA was prepared, the detailed assessment of climate risks and adaptation options that was done still constitutes a good-practice example.

Sources: Asian Development Bank (ADB). 2008. Report and Recommendation of the President to the Board of Directors: Proposed Loan to the Cook Islands for the Avatiu Port Development Project. Manila; Asian Development Bank (ADB). 2013d. Report and Recommendation of the President to the Board of Directors: Proposed Loan and Administration of Grant to the Socialist Republic of Viet Nam for the Central Mekong Delta Region Connectivity Project. Manila; Asian Development Bank (ADB). 2014b. Central Mekong Delta Region Connectivity Project: Rapid Climate Change Threat and Vulnerability Assessment. Manila; authors' formulation.

76. The economic and financial analysis of climate risks and adaptation in CRM could be enhanced though the use of the same five principles presented above. The CRM procedures should be moved upstream (Principle 1), for a more strategic analysis of climate risks and identification of adaptation opportunities in country programming. A differentiated approach must also be applied to the cost-benefit analysis of adaptation in light-touch and detailed projects (Principle 2). Economic issues, which are currently examined far too late in the project cycle, must be considered earlier in the process in all CRAs. Efforts made to understand the project better (Principle 3) and analyze risks (Principle 4) should take economic considerations into account. Finally, economic analysis must become part of adaptation analysis. In light-touch projects, it could take the form of economic principles for low- and no-regret actions, with associated development of material to help project teams (Principle 5). Economics may also be used in decision making under uncertainty for in-depth Type 1 projects, where detailed analysis is warranted. In both cases, it would be useful to develop a set of economic good-practice case study examples. 
Principle 5b (for in-depth CRAs): Early adaptation options should be identified, given the timing and the degree of uncertainty. These CRAs should focus on no- and low-regret adaptation, identify climate-smart design (considering uncertainty), and introduce adaptive management.

\section{Adaptation (Type 2) Projects}

77. While the focus of this working paper is on climate proofing projects, the workshop and subsequent discussions also generated useful lessons for adaptation (Type 2) projects, i.e., those where the primary aim is adaptation. Some of the key lessons are outlined below. It is recommended that these findings be taken forward separately (from those with a climate proofing focus), in a subsequent update of the CRM process, especially given the likely scale-up in ADB climate finance in line with the Strategy 2030.

78. For adaptation (Type 2) projects, Principle 1 (moving upstream) is even more pertinent, as it will help ensure strategic consideration of climate risks to help build a pipeline of adaptation investment projects. Type 2 projects should ideally arise from a country-, sector-, or region-wide assessment of climate risks to inform the project's design concept. Therefore, the climate risk assessment might be applied to the region, sector, or community itself, as distinct from the project.

79. A number of insights relate to the concept and preparation phases of adaptation projects. In the project concept note, climate risks should form the basis for the problem tree, and the project theory of change should focus primarily on delivering adaptation outcomes. Adaptation should be the central output and outcome of Type 2 projects, with associated key indicators. Workshop participants emphasized the need for a single integrated team with climate expertise to design Type 2 projects in the preparation phase- $a$ requirement that, the participants said, should be reflected in the terms of reference for the TRTA. The workshop discussion identified that integration and analysis may be challenging to deliver in practice, as it would require each of the major team positions to have core expertise in climate change. This will require capacity building and awareness raising in $A D B$, as well as new skills for service contractors. This emphasis on adaptation should also be reflected in the economic analysis and EIRR analysis for Type 2 projects. A more focused analysis of climate risks and a more comprehensive appraisal of the costs and benefits of the proposed adaptation measures will have to become part of the core design and development of the project. ${ }^{18}$

80. There is also a need to use decision-led climate information in adaptation projects (Principle 4). For many Type 2 projects, an in-depth analysis of climate risks and adaptation options, consistent with the project focus, must be done. This will require a more detailed analysis rather than a light-touch approach or rapid risk assessment. However, there are different forms of Type 2 projects. Some focus on making the system more resilient, rather than on project investments. Others may not require detailed climate risk and adaptation analysis, such as when the investment is a technical assistance, although a strong climate narrative is essential.

81. Finally, the future risks of climate change in the coming decades are so large that new transformational adaptation - a system change, rather than an incremental change in the existing system (Glossary) - might be needed. This represents a new area of programming, and further investigation of transformational adaptation is recommended.

18 For example, a Type 2 project with a high adaptation allocation (50\%-100\%) should be able to demonstrate that it addresses future climate change as well as current climate variability in the problem tree. There should also be an analysis to demonstrate the use of EIRR under future climate change (not just current climate variability). Failure to include such an analysis might entail reputational risk, because it implies that a standard project is being relabeled as an adaptation project. 


\section{STRENGTHENING DOWNSTREAM-THE IMPLEMENTATION LEVEL}

82. Besides the need for further development on the upstream side, another finding from the review was the need to consider downstream aspects to ensure that adaptation options are implemented successfully under the project during its implementation phase. Too often, Board approval is seen as the end point, so there is a need to help translate the CRA findings into implementation.

83. These downstream activities are already captured in steps 17-20 of the current guidance (Figure 5). However, discussions during the workshop identified some challenges associated with these steps. In particular, downstream tasks, as distinguished from core project preparation activities and the CRA, should be taken on by a new team. This usually means it is the DMC counterparties that are responsible for implementing the recommended elements for climate risk management and adaptation. As a result, it may be difficult to make certain that planned adaptation activities are continued downstream into the project administration manual (PAM) and that there is sufficient awareness and support for resident missions for implementation. This transfer is clearly more challenging when adaptation elements are complex, highlighting issues around institutional memory and capacity to follow through with results of the CRA process.

Figure 4: The Climate Risk and Adaptation Assessment Process and the Implementation Phase

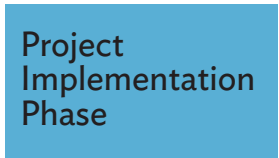

IMPLEMENTATION ARRANGEMENTS

Step 17: Establish arrangements for implementation

Step 18: Identify needs for technical support and capacity building

\section{MONITORING AND EVALUATION}

Step 19: Design the monitoring and evaluation plan, including suitable performance indicators

Step 20: Provide feedback into policymaking and knowledge management

CRA = climate risk and adaptation assessment.

Source: Asian Development Bank (ADB). 2015a. Economic Analysis of Climate-Proofing Investment Projects. Manila.

84. Climate proofing (Type 1) projects involving flexible or iterative adaptation present other implementation challenges. It is more difficult to execute projects that build flexibility for later upgrade, or iterative monitoring and action, as these projects need to consider how to structure the loan and governance arrangements for subsequent changes to the project, potentially over decades in the future. This can raise issues around the loan conditions and loan covenants, as well as on sequencing of loans. One possible approach is to require projects to prepare an adaptive design and risk management plan (ASCE 2018; UNESCO 2018) that will accompany loan documents, most likely as a section within the 
PAM. There are also complex questions around who will be responsible for monitoring climate change and who will decide on when future actions should be triggered. Finally, there is also the question on how to ensure that institutional memory is in place-within ADB and the member country, and across several decades - to support iterative or flexible adaptation. This is even more complicated with joint public-private projects (e.g., allowable break points or penalty exclusions for future upgrades). Further work to explore these issues is a priority, along with good practice case studies. This might simplify the application of iterative approaches, especially if there are existing templates for loan covenants, PAM documents, to use. Accordingly, there is a need to strengthen the downstream implementation of the CRM and CRA guidance. This leads to the final principle.

Principle 6: CRM activities should encompass downstream implementation, including activities to enable more flexible and iterative adaptation, and to enhance mechanisms for monitoring, evaluation, and learning.

85. Finally, there is an opportunity to extend the design and monitoring framework (DMF) to include more emphasis on collecting implementation experience, such as adaptation outcome or climate resilience metrics and other climate indicators, and to move formally from monitoring and evaluation (M\&E) to a monitoring, evaluation, and learning (MEL) framework. This would provide more explicit feedback and lessons that would help inform and improve future adaptation programming within the ADB portfolio, as well as more ex-post evaluation. Valuable data on the costs and benefits of adaptation, lessons learned from the implementation of iterative projects, etc., could be made available for future CRAs.

\section{CONCLUSION}

86. Taken together, these six guiding principles form the basis for updating the ADB CRM framework, including CRAs for climate proofing projects. Along with other ongoing studies, ${ }^{19}$ the principles are expected to provide the foundation for developing upstream (strategic) and downstream activities, and project-level CRA guidance for both light-touch and detailed CRA (Figure 5). This should lead to an update of the current technical guidance and outline steps (i.e., updates to Figures 2, 3, and 5). The implementation of these principles will streamline the CRM framework with a fit-for-purpose approach, while improving the quality and consistency of CRAs.

19 This includes the emerging work from the technical assistance projects TA9191 (critical infrastructure) and TA9414 (expert pool/good practice), as well as existing information (e.g., ClimeCo on cost benchmarking). 


\section{Figure 5: Principles for Updating ADB's Climate Risk Management and Climate Risk Adaptation Assessment for Climate Proofing (Type 1) Projects}

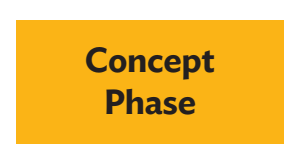

\section{Preparation} Phase
Principle 1: The CRM process should begin upstream, including in the Country Partnership Strategy, to identify climate change risks for regions, sectors, and communities. This informs and supports the development of a pipeline of adaptation projects and climate proofing activities.
Principle 2: The type of climate proofing project-and suitability for light-touch assessment-should be identified early on in the concept phase to ensure that the time and resources required for fit-for-purpose CRA are secured. The lifetime, degree of lock-in, level of precaution needed, and project size should be considered.

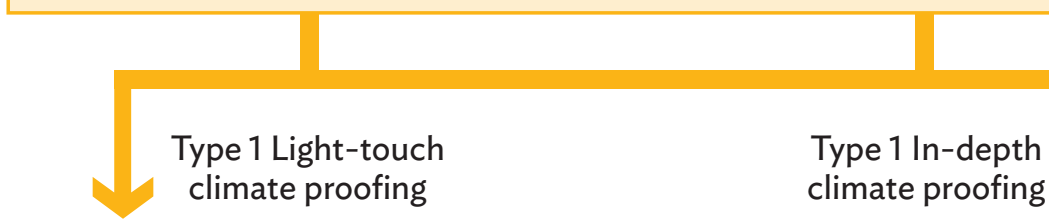

Principle 3: The CRA should begin by focusing on what matters: understanding key climate risks that can affect the project objectives and outcomes. Climate projections come later.

Principle 4: The project risk management context should determine the selection and use of climate information i.e. this should be "decision-led".

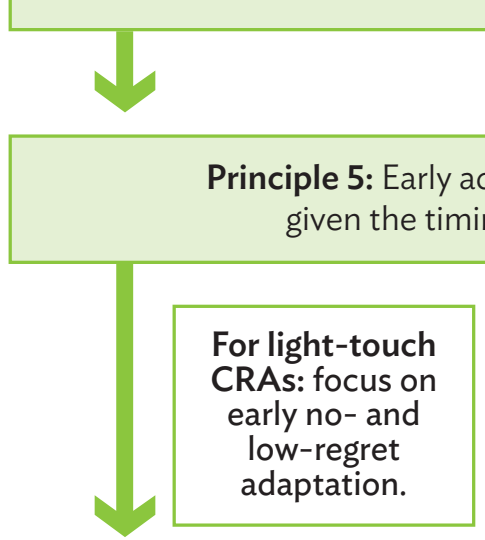

Principle 6: CRM activities should encompass downstream implementation, to enable more flexible and iterative adaptation, and enhance mechanisms for monitoring, evaluation, and learning.

$\mathrm{CRA}=$ climate risk and adaptation assessment, $\mathrm{CRM}=$ climate risk management.

Source: Authors' formulation. 
87. A number of next steps are highlighted, to build on these principles and take forward the update of the CRM and CRAs. These are:

- Rolling out new principles, including training within ADB and its DMCs.

- Developing upstream CRM activities; targeting the entry points of the CPS, COBPs, sector operational plans, and the pre-concept phase; and establishing good-practice examples of strategic analysis.

- Introducing a differentiated decision tree in the CRM system for climate proofing (Type 1) projects, reflecting the two CRAs (light-touch and in-depth). An initial appraisal of the likely categorization of common projects in the ADB portfolio between these two CRA types would also be useful.

- Compiling a set of good-practice examples and knowledge products for light-touch Type 1 CRAs, and developing guidance and supporting material, including rapid assessment guidance (aligned to sector strategies).

- Developing detailed CRA guidance for in-depth climate proofing (Type 1) projects, with focused support for major project investment types, and creating draft terms of reference that integrate these activities within the main TRTA analysis, with supporting good practice studies.

- Enhancing the economic and financial analysis of climate risks and adaptation, using the same principles outlined above. This enhancement should include differentiated approaches to the treatment of light-touch and in-depth CRAs, and would benefit from economic case studies. It should also include material to support the economic analysis of light-touch projects, e.g., benchmarking costs, lookup tables, good-practice case studies, as recommended in the economic review (para. 73).

- Undertaking further work to overcome the barriers to downstream adaptation implementation, and developing good-practice examples for ADB.

- Developing a more structured process for learning within the CRM framework.

- Investigating the implications of the recent ADB commitment, together with other MDBs, for Paris Alignment, and whether this requires further CRM and CRA updates, ${ }^{20}$ and also undertake early scoping work on transformational adaptation.

88. Finally, it is recommended that a similar exercise be undertaken for adaptation (Type 2) projects, including a set of principles, from the strategic level and throughout the project cycle.

20 The announcement was made at the 24th Session of the Conference of the Parties to the United Nations Framework Convention on Climate Change(UNFCCC) (https://www.ebrd.com/news/2018/mdbs-make-joint-declaration-on-climatefinance-alignment.html). The Paris alignment is a joint approach to ensure alignment with the 2015 Paris Agreement (the goal of limiting the global average temperature increase to well below $2^{\circ} \mathrm{C}$ above pre-industrial levels and pursuing efforts to limit it to $1.5^{\circ} \mathrm{C}$ ). The commitment includes aligning MDB operations to mitigation and climate resilience goals, increasing climate finance capacity-building support for countries and other clients, and emphasizing climate reporting. According to the ADB announcement: MDBs "will be active in managing physical climate change risks, in a manner consistent with climate-resilient development, and in identifying opportunities to make our operations more climate-resilient." 


\section{GLOSSARY}

The following main definitions used in this report draw on the Fifth Assessment Report of the Intergovernmental Panel on Climate Change (IPCC) and the IPCC core concepts.

Adaptation. The process of adjustment to actual or expected climate and its effects. In human systems, adaptation seeks to moderate or avoid harm or exploit beneficial opportunities. In some natural systems, human intervention may facilitate adjustment to expected climate and its effects. This can be differentiated into the following types of actions:

- Incremental adaptation. Adaptation actions where the central aim is to maintain the essence and integrity of a system or process at a given scale. (Source: IPCC 2014)

- Transformational adaptation. Adaptation that changes the fundamental attributes of a system in response to climate and its effects. (Source: IPCC 2014)

Adaptation pathway. A generic term that involves the analysis of adaptation options over time as risk levels change. The term "adaptation pathway" has been applied to different approaches, including adaptation road maps, adaptive management, and dynamic adaptation route maps.

Climate variability. Variations in the mean state of the climate and other climate-related statistics (such as standard deviation or the occurrence of extremes) on all spatial and temporal scales beyond individual weather events. Variability may be due to natural internal processes within the climate system (internal variability) or to variations in natural or anthropogenic external forcing (external variability). (Source: IPCC 2014)

Climate projection. The simulated response of the climate system to a scenario of future emission or concentration of greenhouse gases and aerosols, generally derived using climate models. Climate projections are distinguished from climate predictions by their dependence on the emission/ concentration/radiative-forcing scenario used, which is in turn based on assumptions concerning, for example, future socioeconomic and technological developments that may or may not be realized. (Source: IPCC 2014)

Climate proofing. A shorthand term for identifying risks to a development project, or any other specified natural or human asset, as a consequence of climate variability and change, and ensuring that those risks are reduced to acceptable levels through long-lasting and environmentally sound, economically viable, and socially acceptable changes implemented at one or more of the following stages in the project cycle: planning, design, construction, operation, and decommissioning. (Source: ADB 2005)

Exposure. The presence of people, livelihoods, species or ecosystems, environmental functions as well as services and resources, infrastructure, or economic, social, or cultural assets in places and settings that could be adversely affected. (Source: IPCC 2014)

Hazard. The potential occurrence of a natural or human-induced physical event or trend that may cause loss of life, injury, or other health impact, as well as damage and loss to property, infrastructure, livelihoods, service provision, ecosystems, and environmental resources. The IPCC commonly uses the term "hazard" to refer to climate-related physical events or trends or their physical impact. (Source: IPCC 2014) 
Lock-in. An action or decision taken today that "locks in" the potential for future climate risk and is difficult or costly to reverse or change later on. This includes decisions or investments that involve a long lifetime, the potential for large future climate risks, and a degree of (quasi-) irreversibility.

Resilience. The capacity of social, economic, and environmental systems to cope with a hazardous event or trend or disturbance, responding or reorganizing in ways that maintain their essential function, identity, and structure while also maintaining the capacity for adaptation, learning, and transformation. (Source: IPCC 2014)

However, the term "resilience" is now used very widely and is defined in this document as the capacity to resist, respond to, or recover from natural hazards and maintain essential infrastructure function, both at the present time and over the medium and long term. These hazards include geophysical and weatherrelated hazards, with changes in weather extremes and climate trends reflecting changes in the Earth's climate and in exposure and vulnerability to those events and trends (Source: ADB 2020)

Risk. The potential for adverse consequences where something of value is at stake and where the occurrence and degree of an outcome is uncertain. In the assessment of climate impact, the term "risk" is often used to refer to the potential for adverse consequences of a climate-related hazard on lives, livelihoods, health and well-being, ecosystems and species, economic as well as social and cultural assets, services, and infrastructure. Risk results from the interaction of vulnerability, its exposure over time (to the hazard), and the (climate-related) hazard and the likelihood of its occurrence. (Source: IPCC 2014)

Socioeconomic scenario. A scenario that describes a possible future in terms of population, gross domestic product, and other socioeconomic factors relevant to understanding the implications of climate change. (Source: IPCC 2014)

Vulnerability. The propensity or predisposition to be adversely affected. Vulnerability encompasses a variety of concepts and elements including sensitivity or susceptibility to harm and lack of capacity to cope and adapt. (Source: IPCC 2014) 


\section{REFERENCES}

African Development Bank (AfDB), Asian Development Bank (ADB), European Bank for Reconstruction and Development (EBRD), European Investment Bank (EIB), Inter- American Development Bank (IDB), IDB Invest, IDB Lab, and Islamic Development Bank. 2019. 2018 Joint Report on Multilateral Development Banks Climate Finance. http://dx.doi.org/10.18235/0001736.

American Society of Civil Engineers (ASCE). 2018. Climate-Resilient Infrastructure: Adaptive Design and Risk Management. Bilal M. Ayyub, ed. Michigan.

Asian Development Bank (ADB). 2005. Climate Proofing: A Risk-based Approach to Adaptation. Manila

-2008. Report and Recommendation of the President to the Board of Directors: Proposed Loan to the Cook Islands for the Avatiu Port Development Project. Manila.

2012. Guidelines for Climate Proofing Investment in Agriculture, Rural Development, and Food Security. Manila.

-2013a. Economics of Climate Change in East Asia. Prepared by Michael Westphal, Gordon Hughes, and Jörn Brömmelhörster. Manila.

- 2013b. The Economics of Climate Change in the Pacific. Policy brief prepared by Robert Guild and Cyn-Young Park. Manila.

_. 2013c. Guidelines for Climate Proofing Investment in the Energy Sector. Manila.

- 2013d. Report and Recommendation of the President to the Board of Directors: Proposed Loan and Administration of Grant to the Socialist Republic of Viet Nam for the Central Mekong Delta Region Connectivity Project. Manila.

- 2014a. Assessing the Costs of Climate Change and Adaptation in South Asia. Report prepared by Mahfuz Ahmed and Suphachol Suphachalasai. Manila.

- 2014b. Central Mekong Delta Region Connectivity Project: Rapid Climate Change Threat and Vulnerability Assessment. Manila.

. 2014c. Climate Risk Management in ADB Projects. Manila.

—. 2014d. Technologies to Support Climate Change Adaptation in Developing Asia. Manila.

- 2015a. Economic Analysis of Climate-Proofing Investment Projects. Manila.

2015b. Southeast Asia and the Economics of Global Climate Stabilization. Manila.

. 2016a. Economics of Climate Change in Central and West Asia: Adaptation Component. Manila (TA 8119-REG).

_. 2016b. Guidance Note on Counting Climate Finance at ADB. Manila. 
_-_. 2017a. Disaster Risk Assessment for Project Preparation: A Practical Guide. Manila.

_-_. 2017b. Guidelines for the Economic Analysis of Projects. Manila.

- - - 2017c. Report and Recommendation of the President to the Board of Directors: Proposed Loan to the Socialist Republic of Viet Nam for the Basic Infrastructure for Inclusive Growth in the Northeastern Provinces Sector Project. Manila.

-_- 2018a. Adjusting Hydrological Inputs to Road Design for Climate Change Risk Based on Extreme Value Analysis. Manila (TA 8957-VIE).

2018b. Information Sources to Support ADB Climate Risk Assessments and Management: Technical Note. Manila.

- 2018c. Strategy 2030: Achieving a Prosperous, Inclusive, Resilient, and Sustainable Asia and the Pacific. Manila.

2020. Climate Change Adjustments for Detailed Engineering Design with Worked Examples from Viet Nam. Manila.

Asian Development Bank (ADB) and World Bank Group. 2020. Climate Risk Country Profiles. Manila.

European Commission. 2017. Economics of Climate Change Adaptation in Europe (ECONADAPT) Project: Inventory and Look-Up Tables. Brussels:

https://econadapt-toolbox.eu/data-sources and https://econadapt-library.eu/.

Fankhauser, Samuel, Joel B. Smith, and Richard Tol. 1999. Weathering Climate Change: Some Simple Rules to Guide Adaptation Investments. Ecological Economics. 30 (1). pp. 67-78.

Haasnoot, Marjolijn, Jan H. Kwakkel, Warren E. Walker, and Judith ter Maat. 2013. Dynamic Adaptive Policy Pathways: A Method for Crafting Robust Decisions for a Deeply Uncertain World. Global Environmental Change. 23 (2; April). pp. 485-498. https://doi.org/10.1016/j.gloenvcha.2012.12.006.

Intergovernmental Panel on Climate Change (IPCC). 2007. Appendix I: Glossary. Climate Change 2007: Impacts, Adaptation and Vulnerability. Contribution of Working Group II to the Fourth Assessment Report of the IPCC. https://archive.ipcc.ch/pdf/assessment-report/ar4/wg2/ar4-wg2-app.pdf.

- 2014. Annex II: Glossary. Climate Change 2014: Mitigation of Climate Change. Contribution of Working Group III to the Fifth Assessment Report of the IPCC. https://www.ipcc.ch/site/assets/uploads/2018/02/WGIIAR5-AnnexII_FINAL.pdf.

International Centre for Environmental Management (ICEM). 2012. Mekong Delta Central Connectivity Project: Rapid Climate Change Threat and Vulnerability Assessment. Consultant's report submitted to the Asian Development Bank. Hanoi.

International Hydropower Association (IHA). 2019. Hydropower Sector Climate Resilience Guide. London. https://www.hydropower.org/publications/hydropower-sector-climate-resilience-guide. 
Organisation for Economic Co-operation and Development (OECD). 2015. Climate Change Risks and Adaptation: Linking Policy and Economics. Paris: OECD Publishing.

http://dx.doi.org/10.1787/9789264234611-en.

- 2016. OECD DAC Rio Markers for Climate: Handbook. Paris: OECD Development Assistance Committee. http://www.oecd.org/dac/environment-development/Revised\%20climate\%20 marker\%20handbook_FINAL.pdf.

Ranger, Nicola, Antony Millner, Simon Dietz, Sam Fankhauser, Ana Lopez, and Giovanni Ruta. 2010. Adaptation in the UK: A Decision-Making Process. Policy briefing note prepared for the Adaptation Sub-Committee of the Committee on Climate Change, UK. London: Grantham Research Institute on Climate Change and the Environment and Centre for Climate Change Economics and Policy.

Ray, Patrick A., and Casey M. Brown. 2015. Confronting Climate Uncertainty in Water Resources Planning and Project Design: The Decision Tree Framework. Washington, DC: World Bank. DOI:10.1596/978-1-4648-0477-9. License: Creative Commons Attribution CC BY 3.0 IGO.

UNESCO. 2018. Climate Risk Informed Decision Analysis (CRIDA): Collaborative Water Resources Planning for an Uncertain Future. Prepared by Guillermo Mendoza, Ad Jeuken, John H. Matthews, Eugene Stakhiv, John Kucharski, and Kristin Gilroy. Paris. http://agwaguide.org/docs/CRIDA_Nov_2018.pdf.

Warren, Rachel F., Robert L. Wilby, Kathryn Brown, Paul Watkiss, Richard A. Betts, James M. Murphy, and Jason A. Lowe. 2018. Advancing National Climate Change Risk Assessment to Deliver National Adaptation Plans. Philosophical Transactions of the Royal Society A: Mathematical, Physical and Engineering Sciences. 376 (2121). ISSN: 1364-503X. DOI: 10.1098/rsta.2017.0295.

Watkiss, Paul. 2011. Aggregate Economic Measures of Climate Change Damages: Explaining the Differences and Implications. Wiley Interdisciplinary Reviews: Climate Change. 2 (3). pp. 356-372. https://doi.org/10.1002/wcc.111.

2018. Strengthening Adaptation Economics in the Asian Development Bank. Report submitted to the Asian Development Bank. Manila.

Watkiss, Paul, and Alistair Hunt. 2011. Method for the Adaptation Economic Assessment to Accompany the UK Climate Change Risk Assessment (CCRA). Final report submitted to the Department for Environment, Food \& Rural Affairs, UK, by HR Wallingford Ltd (contract CEOSA 0901). May.

Watkiss, Paul, Alistair Hunt, William Blyth, and Jillian Dyszynski. 2015. The Use of New Economic Decision Support Tools for Adaptation Assessment: A Review of Methods and Applications, towards Guidance on Applicability. Climatic Change. 132 (3). pp. 401-416. https://doi.org/10.1007/s10584014-1250-9.

Wilby, Robert L. 2017. Strengthening ADB Business Processes: Project Level Guidance and Operational Frameworks for Climate-Resilient Investments. Report submitted to the Asian Development Bank. Manila.

Wilby, Robert L., and Rod Keenan. 2012. Adapting to Flood Risk under Climate Change. Progress in Physical Geography. 36 (3). pp. 348-378. ISSN: 0309-1333. DOI: 10.1177/0309133312438908. 



\section{Principles of Climate Risk Management for Climate Proofing Projects}

Since 2014, the Asian Development Bank (ADB) has adopted the climate risk management (CRM) approach to scale up investments in climate change adaptation. This working paper recommends a set of guiding principles that can be applied to streamline the application of the approach aligned with the main phases of the ADB project cycle-based on the lessons learned from implementation of the CRM approach over the years.

\section{About the Asian Development Bank}

ADB is committed to achieving a prosperous, inclusive, resilient, and sustainable Asia and the Pacific, while sustaining its efforts to eradicate extreme poverty. Established in 1966, it is owned by 68 members -49 from the region. Its main instruments for helping its developing member countries are policy dialogue, loans, equity investments, guarantees, grants, and technical assistance. 